\title{
Von Abwehrgefechten zu Dialogansätzen: Die Auseinandersetzungen um Skandalfilme in der katholischen Filmarbeit
}

\author{
von Peter Hasenberg
}

\section{Einleitung}

Die Beschäftigung der katholischen Kirche mit dem Medium Film hat eine lange Tradition, die bis an die Anfänge der Filmgeschichte zurückreicht. Wie kaum einem anderen Bereich zeitgenössischer Kultur hat die Kirche dem Film ihre Aufmerksamkeit gewidmet ${ }^{1}$. Heute hat sich die katholische Filmarbeit durch ihre filmkritischen Publikationen wie dem Periodikum "film-dienst" 2, der ,dienstältesten" deutschen Filmzeitschrift und vor allem durch das "Lexikon des Internationalen Films", in erster Auflage 1987 erschienen, in der filmkundigen Branche unbestreitbar einen Namen gemacht; die Publikationen sind für Filmwissenschaftler und Filmliebhaber unverzichtbar aufgrund ihres umfassenden Anspruchs. Im Bewußtsein der Öffentlichkeit hat sich das Verhältnis von Kirche und Film vielfach anders eingeprägt: die Kirche erscheint als strenge Zensurinstanz, die sich bei moralisch fragwürdigen oder unterstellt blasphemischen Filmen mit Forderungen nach dem Verbot der beanstandeten Werke zu Wort meldet. Der "film-dienst" der $50 \mathrm{er}$ und 60er Jahre wurde schon von Kritikern zu einem "einflußreichen Organ klerikaler Nebenzensur im Dienst besonders reaktionärer Teile der Bourgeoisie/3 abgestempelt. Dieses Bild ist geprägt durch Ereignisse um "Skandalfilme", die in der Öffentlichkeit z.T. hohe Wellen geschlagen haben. Betrachtet man katholische Filmarbeit nur im Hinblick auf die Auseinandersetzungen um die "Skandalfilme", wird die Perspektive sicherlich verzerrt, denn die Zahl der als bemerkenswert, sehenswert empfohlenen Filme übersteigt die der "Skandalfilme“ bei weitem. Dennoch ist es sinnvoll, sich der katholischen Filmarbeit

Dr. phil. Peter Hasenberg (geb. 1953) ist Filmreferent in der Zentralstelle Medien der Deutschen Bischofskonferenz in Bonn und Vorsitzender der ,Katholischen Filmkommission für Deutschland'.

1 Vgl. zur Geschichte der Katholischen Filmarbeit bis 1945 Heiner Schmitt, Kirche und Film. Kirchliche Filmarbeit von ihren Anfängen bis 1945, Schriften des Bundesarchivs 26, Boppard/Rh. 1978.

2 Im folgenden wird aus Gründen der Einheitlichkeit die nach dem 1964 eingeführten Logo übliche Schreibweise "film-dienst" verwendet, andere früher benutzte Schreibweisen ("Filmdienst", „Film-Dienst") bleiben berücksichtigt.

3 Klaus Kreimeier, Kino und Filmindustrie in der BRD. Ideologieproduktion und Klassenwirklichkeit nach 1945; Kronberg/Ts. 1973, 200. 
gerade in exemplarischer Behandlung der umstrittenen Filme zu nähern: zum einen ist dieses Feld nicht hinreichend aufgearbeitet, so daß eine um Differenzierung bemühte Darstellung dazu beitragen kann, die Auseinandersetzungen nicht unter der klischeehaften Schablone "Kirche ruft nach Verbot" zu sehen; zum anderen finden sich in den Auseinandersetzungen um Skandalfilme so etwas wie markante Wegsteine in der Geschichte der katholischen Filmarbeit. Die Filme, um die in der Öffentlichkeit heftigst gestritten wurde, haben auch die katholische Filmkritik herausgefordert, d.h. es fanden ausgiebige Diskussionen statt, und der Standpunkt wurde dabei besonders klar herausgearbeitet, so daß sich anhand dieser Fälle exemplarisch der jeweilige Stand in der Katholischen Filmarbeit zuverlässig ablesen läßt.

Der folgende Beitrag versucht, die Entwicklung nachzuzeichnen. Dabei stehen neben dem Uberblick über die einzelnen Epochen einige Beispiele exemplarisch im Mittelpunkt, Filme wie "Die Sünderin" (1950), "Das Schweigen" (1963) oder "Die letzte Versuchung Christi" (1988). Bevor die Fälle im einzelnen untersucht werden, sind einige Vorbemerkungen vorauszuschicken:

(1) Die Frontlinien in den Auseinandersetzungen sind nie so klar zu ziehen, daß auf der einen Seite der Film und auf der anderen "die" Kirche steht. An der Diskussion sind in jedem Fall unterschiedliche Gruppen innerhalb der Kirche beteiligt: es gibt ja nach Einzelfall offizielle Stellungnahmen der Deutschen Bischofskonferenz oder deren Publizistischer Kommission oder der Zentralstelle Medien, zusätzlich oder flankierend gibt es mitunter Einzelstellungnahmen von Bischöfen, es gibt die veröffentlichten Kritiken und Gutachten der Katholischen Filmkommission, es gibt Stimmen bestimmter Verbände und Gruppen, die sich kritisch zum Inhalt äußern bzw. mit Forderungen nach Verboten zu Wort melden.

(2) Es geht in den Auseinandersetzungen nie allein um die Inhalte der Filme und um Fragen der Theologie oder Kunst. Andere Faktoren wie Fragen des Jugendschutzes, die Kritik an bestimmten Institutionen (Freiwillige Selbstkontrolle der Filmwirtschaft, Filmförderungseinrichtungen) oder kircheninterne Konflikte spielen in der Regel mit hinein.

(3) Die einzelnen Stellungnahmen sind vollkommen unterschiedlich zu gewichten. Die inhaltlich fundiertesten Stellungnahmen findet man in der professionellen katholischen Filmkritik. Es gibt daneben aber immer auch das Phänomen, daß ein Großteil der Stellungnahmen ohne Sichtung des Films abgegeben wird, so daß die Reaktionen gar nicht auf den Film, sondern auf Berichte aus zweiter Hand bezogen sind.

Als Phänomene sind die Auseinandersetzungen um die "Skandalfilme" nur multifaktoriell angemessen zu beschreiben. Viele Details und Motivationen einzelner und bestimmter Gruppen sind präzise kaum zu 
erfassen. Im folgenden soll jedoch der Schwerpunkt auf der Filmkritik bzw. der Filmkommission liegen, weil sich hier tatsächlich eine Auseinandersetzung mit dem Medium Film und der Frage der Rezeption vollzieht.

\section{Zielsetzungen der katholischen Filmkritik}

Nach dem 2. Weltkrieg erfolgte eine Reorganisation der katholischen Filmarbeit, die durch die Kulturpolitik der Nationalsozialisten zerschlagen worden war. Als Schwerpunkt erwies sich die katholische Filmpublizistik, die kurz nach Kriegsende 1947 begründet wurde und bis heute ein Kernstück der filmkulturellen Bemühungen der Kirche geblieben ist. Das Flagschiff der katholischen Filmarbeit wurde der „film-dienst". 1947 als „Filmdienst der Jugend“ gegründet, wurde er 1949 das offizielle Organ der in jenem Jahr gegründeten Katholischen Filmkommission für Deutschland4. Den Anstoß zur Gründung des „film-dienstes" gab nicht zuletzt ein Filmskandal, den die erste deutsche Produktion auslöste. Der Film „Sag die Wahrheit" (1947) löste Protest aus. Klaus Brüne, der als Student mit Kommilitonen den "film-dienst" gründete, erinnert sich: „Der Film von Helmut Weiß (Regie) und Ernst Marischka (Buch) erwies sich als ein nichtsnutzig-frivoles Lügenlustspiel in jenem Ablenkungsstil, den Goebbels im Krieg für angebracht gehalten hatte. Heute kaum zu glauben: Studenten in Bonn und Münster, Jugendliche in Osnabrück, Bergisch-Gladbach und anderenorts in der britischen Zone strömten zu zornigen Protesten vor die Lichtspielhäuser. ${ }^{\star 5}$

Der Chefredakteur Brüne formuliert in der ersten Ausgabe des "Filmdienstes der Jugend" das Programm der neuen Filmpublikation, die sozusagen aus dem Geist des Widerstandes gegen schlechte' Filme geboren wird, deren potentielle Gefahren durch die Beispiele der Nazi-Propagandafilme den Mitarbeitern der neuen Publikation vertraut waren. Adressat der Filmbesprechungen sind „die Jugendseelsorger, die Lehrer, die Jugendführer und nicht zuletzt die Eltern"6. Der Film wird ganz auf der Linie der bewahrpädagogischen Argumentation, die den Film seit seiner Geburtstunde begleitet hat - in erster Linie als Gefahr für das jugendliche Publikum gesehen, dem eine besondere Anfälligkeit für die Verführungskünste des Films attestiert wird: „[...] seine geringe

4 Zur Geschichte des "film-dienstes" und der Katholischen Filmkommission vgl. Wilhelm Bettecken, Dienst am Film - Dienst am Menschen. 40 Jahre ,film-dienst,, 1947-1987, Festschrift, Köln 1987; zur Gründung der Filmkommission bes. $16 \mathrm{ff}$.

5 Klaus Brüne, „Damals fing auch der Filmdienst an”, in: Bernd Börger/Karin Kortmann ( $\mathrm{Hg}$.$) , Ein Haus für junge Menschen. Jugendhaus Düsseldorf$ 1954-1994. Beiträge zur Geschichte der katholischen Jugendarbeit, Düsseldorf 1994, 67-71, hier, 68.

6 Klaus Brüne, in: Filmdienst der Jugend, Lfg. 1 (1948) 1. 
geistige Selbsttätigkeit, seine Disposition für Massenansteckung, seine Affektbestimmtheit und die daraus folgende Urteilsschwäche müssen durch eine systematische Erziehung zu kritischem Sehen, kritischem Hören und kritischem Denken überwunden werden." (ebd.)

Im Hinweis auf die Gefahr der "Massenansteckung" klingt die Erfahrung der Hitlerjahre deutlich an. Auch wenn das filmerzieherische Programm stark von einer Führung der Jugendlichen ausgeht, ist doch das Ziel die kritische Urteilsfähigkeit. Die Besprechungen werden auch verstanden als Anregung zur Jugendarbeit mit einem doppelten Zweck: Film- und Glaubensbildung als Mittel zur Bildung des kritischen urteilsfähigen Menschen: "Die psychologisch fundierte öftere Filmbesprechung in der Jugendgruppe nach gemeinsamem Filmbesuch ist ein Weg dahin. Durch sie kann selbst aus einem unterdurchschnittlichen Film ein Bildungsinstrument werden, ja mehr noch: ein Anstoß zu selbständiger Auseinandersetzung mit der heidnischen Umwelt, eine Art - vom Gegensatzbewußtsein ausgehende - Glaubensschulung." (ebd.)

Die Auseinandersetzung mit schlechten Filmen ist daher nicht von vornherein ausgeschlossen, auch wenn diese nur im Sinne einer engen Verzweckung, instrumentalisiert als abschreckendes Gegenbeispiel, eingeordnet werden. Besonderer Wert wird auf die Ausbildung einer sachgerechten Besprechungsmethode gelegt, die die besonderen formalen Möglichkeiten des Films berücksichtigt: „Ihr Ausgangspunkt dürfte keine enge Moralschnüffelei, sondern eine ganzheitliche Schau des Films sein." (ebd.)

Im November 1948 wird erstmals unter dem Begriff "Filmdienst" eine Filmliste nach dem Notensystem des Internationalen katholischen Filmbüros (O.C.I.C. - Office Catholique Internationale du Cinéma) veröffentlicht. In seinem Geleitwort erläutert der zuständige ,Filmbischof' Dr. Wilhelm Berning, Osnabrück, die Notenbewertung von kirchenoffizieller Seite" . Die Akzentsetzung ist hier eine andere als im "film-dienst"-Programm, da es nur um die Notenbewertung, nicht um die Kritiken an sich geht. In den Noten drücke sich - so der "Filmbischof" - eine Beurteilung "nur vom religiösen Standpunkt aus" aus; dagegen wird die ganzheitliche Beurteilung nach künstlerischer und technischer Qualität als Aufgabe der „Pressekritik“ gesehen. Die Listen sollen Informationen für die eigene Orientierung der Gläubigen geben. Generelle Vorbehalte gegenüber dem Film schlagen noch durch: "Diese Listen sind nicht eine kirchliche Empfehlung des Filmbesuches an sich. Sie sind nur eine Beratung [...]." (ebd.) Deutlicher heißt es zu dem Charakter der Beratung, der Rat der Kirche sei „kein im Gewissen unter Sünde

7 Wilhelm Berning, "Geleitwort", in: Filmdienst. Hinweise für den Filmbesuch, hg.v.d. Kirchlichen Hauptstelle für Bild- und Filmarbeit, Köln, November 1948 , o.S. 
verpflichtendes Gebot" (ebd.). Und weiter: "Sie [d.h. die Noten] unterscheiden sich also von dem ausdrücklich gegebenen Verbot, etwa Bücher zu lesen, welche im kirchlichen ,Index', dem Verzeichnis verbotener Bücher, namentlich aufgeführt sind." (ebd.) Die Empfehlungen des "Filmbischofs' enthalten auch bereits die Anregung zur Gründung der Filmliga: "Alle Katholiken Deutschlands sollen den ernsten und stillen Vorsatz ablegen, oder, wo es möglich ist, in öffentlicher Feier in der Kirche das Versprechen an ihre Seelsorger geben, keinen Film zu besuchen, der ihrem religiösen und sittlichen Leben Gefahr bringen könnte oder welcher Glauben und Sitte des Christentums angreift oder beleidigt." (ebd.)

Durchweg ist die Sicht des Films als einer besonders einflußreichen, aber potentiell gefährlichen Größe vorherrschend und folgt Leitlinien, die Pius XI. in seiner Filmenzyklika "Vigilanti cura" von 1936 aufgestellt hat ${ }^{8}$. Diesem Schreiben, das als "Grundgesetz katholischer Filmarbeit ${ }^{\prime \prime}$ angesehen wird, hat man zu Recht einen hohen Stellenwert zugesprochen. Schon diese Enzyklika steht im Kontext kirchlicher Bemühungen zur Abwehr der gefährlichen Filme. Kein einzelner Skandalfilm ist Anlaß für die "wachsame Sorge“ (Titel!) des Papstes, sondern die generelle Häufung der "Darstellung von Sünden und Lastern" im Filmschaffen der damaligen Zeit10. Die positiven Möglichkeiten des Films werden durchaus anerkannt, der Film wird im Bereich der Kunst angesiedelt, was keineswegs selbstverständlich ist, aber gerade deshalb wird als höchste Norm die Moral aufgestellt: „Es hat eben die Kunst diese wesentliche Aufgabe, die schon aus ihrem eigenen Daseinsgrund hervorgeht, daß sie nämlich eine Vervollkommnung des Menschen, der ein moralisches Wesen ist, darstellt, und daß sie infolgedessen selber moralisch sein muß." (30)

Dem "guten Film", der positive Ziele verfolgt - Unterhaltung, Vermittlung von Kenntnissen, Förderung des Verständnisses unter den Nationen, Verteidigung der Tugend und der sozialen Gerechtigkeit -, steht der böse, unmoralische Film gegenüber, der "Gelegenheit zur Sünde“ (33) bietet. Daraus erwächst der konkrete praktische Vorschlag des Papstes, dem Beispiel der amerikanischen „Legion of Decency“ zu folgen, einer Organisation, zu der sich 1933 Katholiken in den USA zusammenschlossen, um Einfluß auf die Filmindustrie Hollywoods zu nehmen. Zur Vermeidung von Zensurmaßnahmen in einzelnen Staaten hatte man in den USA bereits das "Hays Office", benannt nach dem ersten Leiter, dem ehemaligen Generalpostmeister Will $H$. Hays, gegründet, und unter Mitwirkung des Jesuiten Daniel S. Lord war ein Regelkatalog aufgestellt worden, der Produzenten angab, welche

8 Zit.n. Katholische Filmkommission für Deutschland (Hg.), Dokumente Katholischer Filmarbeit, Katholisches Filmheft Nr. 7, Düsseldorf 1956, 29-38.

9 Bettecken, a.a.O., 7.

10 "Vigilanti cura", a.a.O., 29. 
Themen und Motive zu vermeiden seien. Die Gründung der "Legion" diente unter anderem der Durchsetzung dieses „Production Code"11. Der Vorschlag des Papstes, in jedem Land ein „permanentes nationales Revisionsbüro" (37) einzurichten, wird in der Arbeit des "film-dienstes" bzw. der Katholischen Filmkommission realisiert. Neben der pastoralen Sorge steht schon im päpstlichen Schreiben die praktische und strategisch relevante Einsicht, daß die Filmwirtschaft nur durch die Abstimmung an der Kasse zu treffen ist und ein organisiertes Verhalten der katholischen Zuschauerschaft die Angebote des Kinos verbessern kann.

\section{Amtskirche und Basis gegen "Die Sünderin” (1950)}

„Der Film „Die Sünderin' dürfte jener Film werden, der am stärksten unter allen nach dem Kriege in Deutschland gezeigten Filmen den Widerspruch gesund denkender - auch nichtchristlicher - Kreise herausfordern muß."12 Hellsichtig beschrieb ein (nichtveröffentlichtes) Gutachten der Katholischen Filmkommission vom 17.09.1950 über das Drehbuch die Wirkung, die der Film haben sollte, den "Der Mittag" als eine "ethische Atombombe "... aus Erotik, Exhibitionismus und Blasphemie" 13 bestehend kennzeichnete.

In der Kinogeschichte hat „Die Sünderin" ihren unbestreitbaren Platz als der bis heute bekannteste und größte Leinwandskandal der frühen Nachkriegszeit. Bei heutigen Wiederaufführungen des Films wird der Skandal meist auf die prüde Haltung der Adenauer-Ära als Skandal um ,die nackte Knef' verkürzt dargestellt. Die Sachlage war weitaus komplizierter und ist einer eingehenderen Betrachtung wert.

Die ersten Fälle von ,Skandalfilmen' in der Geschichte der katholischen Filmkritik gab es schon vor der "Sünderin“, aber nicht mit einer vergleichbaren Breitenwirkung. Die Kontroverse um den Film "Sag die Wahrheit" wurde schon erwähnt, später gab es u.a. Streit um Helmut Käutners Film "Der Apfel ist ab" (1948), dem man „Unsittlichkeit, Verhöhnung der religiösen Gefühle und Unmoral" vorwarf ${ }^{14}$ und der selbst zu Klagen bei der Staatsanwaltschaft führte. Ein weiteres Beispiel ist das englische Nonnen-Melodram "Schwarze Narzisse" (1947) von Michael Powell. Gerade an diesem Film zeigt sich deutlich,

11 Zum Gesamtkomplex vom "Hays Office" bis zum "Production Code" vgl. Garth Jowett, Film. The Democratic Art, Boston/Toronto 1976, 164ff; bes. zur „Legion of Decency", 246-256.

12 Klaus Brüne, „Die Sünderin”. Zwölf Monate später. Eine zusammenfassende Untersuchung der Katholischen Filmkommission für Deutschland, Düsseldorf 1952, o.S.

13 Zit.n.: „Die Presse und „Die Sünderin“, fd 4. Jg., Lfg. 8, 23.02.1951, letzte Seite.

14 Werner HeB, "Der Apfel ist ab" (fd 180), in: Filmdienst der Jugend, 2. Jg., Lfg. 2, 08.01.1949. Veröffentlicht wurde die Kritik des evangelischen Filmbeauftragten. 
wie sehr die Urteile unter dem Eindruck der Erfahrung der Hitler-Jahre stehen. Ziel der filmpädagogischen Bemühungen und Jugendschutzüberlegungen ist immer auch, gerade in bezug auf den massenwirksamen Film, das zu korrigieren, was die Propaganda des Dritten Reichs verzerrt hat. Direktor Anton Kochs, damals Leiter der Kirchlichen Hauptstelle für Bild- und Filmarbeit in Köln, schreibt in seiner Stellungnahme im "film-dienst", die ergänzend zur eigentlichen Kritik veröffentlicht wurde: „Für Deutschland ist noch zu bedenken, daß die Haltung der Öffentlichkeit gegenüber Religion, Kirche und ihren Einrichtungen durch die vergangenen nationalsozialistischen Jahre grundlegend beeinflußt worden ist. Selbst wenn dieser Film nicht vor Jugendlichen gezeigt werden darf, so werden doch junge Menschen vom 16. Lebensjahr ab ihn sehen. Gerade diese haben jahrelang unter der systematischen Staatspropaganda gegen religiöse Orden gestanden. ${ }^{\prime \prime} 15$

Was an der hitzigen Debatte um "Die Sünderin" aus heutiger Sicht vielfach nur mit Kopfschütteln zur Kenntnis genommen wird, hatte in der damaligen Zeit einen enormen Stellenwert. Man muß sich die Zeitumstände der frühen Nachkriegszeit in Erinnerung rufen: die Kirchen waren nach dem Untergang des Nazi-Regimes als die wichtigsten moralischen Instanzen in der jungen Bundesrepublik Deutschland tragende Kräfte der Gesellschaft, und das christliche Wertsystem war erstmals explizit als Grundlage der Politik akzeptiert.

Zum Stand der katholischen Filmkritik im Jahr der „Sünderin“ ist zu vermerken, daß bereits vor dem Skandal eine wichtige Neuakzentuierung vorgenommen worden war. Mit seiner 1000. Besprechung hatte der "film-dienst" in Lfg. 1, 1951 eine Neuerung eingeführt, um „Mißverständnisse“ auszuräumen: Es erfolgte eine formale Trennung der „subjektive[n] Filmwürdigung unserer Rezensenten von der moralischen Bewertung der Filme durch die Katholische Filmkommission"16, die als fettgedruckter Vermerk am Ende der Rezension erschien. Dazu wird erläutert: „Im Unterschied zu der formalen Würdigung des signierten Rezensenten, der nur seine persönlichen, individuellen, also irgendwie relativen Gesichtspunkte nennt, stellt die moralische Bewertung bekanntlich das offizielle Urteil der Katholischen Filmkommission für Deutschland heraus, die streng nach den Grundsätzen der christlichen Ethik entscheidet." (ebd.) Dies galt im Prinzip, seitdem der "film-dienst" als Organ der Katholischen Filmkommission für Deutschland fungierte: „Die sittlich-religiöse Bewertung ist einheitlich, die

15 Anton Kochs, Stellungnahme (fd 382), in: Film-Dienst, 2. Jg, Lfg. 32, 24.08.1949). Die Kritik (fd 375), gezeichnet mit "F.", erschien in: Film-Dienst, 2. Jg., Lfg. 31, 12.08.1949).

16 in: Film-Dienst, 4. Jg., Lfg. 2, 15.01.1951, 1. 
künstlerische Bewertung ist individuel1 ${ }^{\mu 17}$, hatte Dir. Kochs in der ersten Ausgabe als Organ der Filmkommission geschrieben. Mit der Einführung der formalen Trennung von Kritikermeinung und Kommissionsgutachten deutet sich eine Problematik der Vermittlung an, die noch ergänzt wird durch das Eingeständnis: Die Kategorisierung nach Ziffern ist "gewiß nicht ganz ideal, denn sie trägt die Gefahr einer gewissen Schablonisierung in sich, aber sie ist praktisch die brauchbarste [...]. ${ }^{\mu 18}$ Die doppelte Stoßrichtung der katholischen Filmkritik - Abwehr des Schlechten, Förderung des guten Films - wird gleichzeitig dadurch unterstrichen, daß empfehlenswerte Filme auf der letzten Seite besonders hervorgehoben werden.

"Die Sünderin" war nicht von vornherein auf Konfrontationskurs mit den Kirchen. Der Regisseur des Films, der für seine Operettenfilme bekannte Österreicher Willi Forst, hatte bereits in einem frühen Stadium die kirchlichen Stellen von sich aus eingeschaltet. Im Sommer 1950 lag das Drehbuch dem Bundestagsauschuß für Ausfallbürgschaften vor, der eine Bürgschaft im Höhe von 285.250 DM gewährte. Fast zeitgleich hatte Forst das Drehbuch auch den kirchlichen Filmbeauftragten zur Kenntnis gegeben mit der Bitte um „Unterstützung bei der Formulierung religiöser Dialoge“. In der Drehbuchfassung hatte der Film noch einen biblischen Bezugsrahmen, der die Hauptfigur Marina in direkte Parallele zu Maria Magdalena setzte. Im Gutachten der Filmkommission über das Drehbuch wird auf fünf Kameraeinstellungen „mit Szenen blasphemischen Charakters" 19 hingewiesen. Zitiert wird im Bericht der Filmkommission dazu z.B. die folgende Einstellung: „Drehbuch: Wir sehen, die schön geformten Füße eines Mannes, der Sandalen träg $t^{\prime}$ und hören ,eine ruhige, volltönende Stimme': ,Wer von euch ohne Sünde ist, der werfe den ersten Stein auf sie!"' (ebd.) Die Wertung der Szenen als blasphemisch ergab sich dadurch, daß sie so eingebaut waren, daß sie als direkte Rechtfertigung der Taten Marinas eingeordnet waren.

Gleichrangig neben die inhaltliche Auseinandersetzung trat die filmpolitische Auseinandersetzung um die Strukturfrage der Freiwilligen Selbstkontrolle der Filmwirtschaft (FSK). Die Kritik der Kirchenbeauftragten richtete sich gegen eine Prüfpraxis, die die Freigabe eines Filmes ermöglichte, der gegen die grundgesetzlich geschützten sittlichen Werte der jungen Bundesrepublik Deutschland verstieß.

Nachdem erstinstanzlich der Arbeitsausschuß der FSK den Film nicht ohne Schnittauflagen für Jugendliche ab 18 Jahren freigeben wollte, erhielt der Film dann doch am 18. Januar 1951 die Freigabe für Jugendliche ab 18 Jahren durch den Hauptausschuß der FSK, und das wenige Stunden vor seiner offiziellen Premiere im "Turmpalast" in

17 Anton Kochs, „Der zweite Abschnitt”, in: Film-Dienst, 2. Jg., Lfg. 21, 03.06.1949, 1.

18 Vgl. Anm. 16

19 Brüne, „Die Sünderin“. Zwölf Monate später“, o.S. 
Frankfurt/M. Die Verantwortlichen für die kirchliche Filmarbeit - der evangelische Filmbeauftragte Pfr. Werner $\mathrm{He} B$ und der Leiter der Kirchlichen Hauptstelle für Bild- und Filmarbeit, Dir. Kochs, reagierten prompt im Einverständnis mit Bischof Lilje, dem Vorsitzenden der EKD, und Erzbischof Berning, dem katholischen "Filmbischof", da die Vertreter der Öffentlichen Hand im Ausschuß überstimmt worden waren. Die Kirchen kündigten die Zusammenarbeit in der FSK auf. In der Debatte um den Film spielte außerdem noch eine andere, strukturelle Frage des Verleihs eine Rolle: die Problematik des Blindund Blockbuchsystems, das die Kinobesitzer zwang, bestimmte Filme eines Verleihs zusammen mit anderen, vorher nicht bekarınten Filmen zu buchen. Der Herzog-Filmverleih versuchte bei Androhung einer Konventionalstrafe von 2000 DM die Kinobesitzer dazu zu zwingen, die „Sünderin“ zu spielen.

Die Haltung der katholischen Filmkritik, d.h. der professionellen kirchlichen Beobachter der Filmszene, war eindeutig ablehnend, wenn auch durchaus differenziert. Klaus Brüne, der damalige verantwortliche Redakteur, gestand dem Film durchaus künstlerische Qualitäten und die Möglichkeit einer aufklärerischen Wirkung zu: „Es soll nicht bestritten werden, daß Forst seinen Film stellenweise mit künstlerischen Mitteln zu Höhepunkten führt, die dem Sehenden eine schreckhafte Analyse des modernen Menschen ermöglichen." ${ }^{20}$ Daneben sind aber so der Kritiker - auch "platteste Entgleisungen (wie die Astloch-Szene)" sowie schwerwiegendere "psychologische Verkürzungen" festzustellen. Gefahren werden vor allem geortet in der "Romantisierung der Prostitution", in der Ästhetisierung, der - hier wird die Kritik der FAZ zitiert - "widerwärtige[n] romantische[n] Verbrämung mit sogenannter Kunst" (ebd.). Ein Haupteinwand richtet sich gegen den "hübsch ästhetisch fotografierten Doppelselbstmord", wobei die ",barmherzige' Tötung auf Verlangen als besonders verhängnisvoll" (ebd.) eingestuft wird, was angesichts der noch lebhaften Erinnerungen an die Euthanasie-Politik im Dritten Reich einen ganz konkreten Hintergrund erhält. Zusammenfassend lautet das Kommissionsgutachten: "Offen laszive Szenen, die oberflächliche Behandlung des Problems der Prostitution, die verklärende Darstellung der wilden Ehe, die als Opfertat motivierte, nicht korrigierte sexuelle Hingabe gegen Geld, sowie die indirekte Rechtfertigung der Tötung auf Verlangen und des Selbstmordes als letzter Lösung sind angetan, demoralisierend zu wirken. Der Film ist deshalb entschieden abzulehnen. (4) “ (ebd.) Die Wertungsnote "4“ bedeutete: "Abzuraten. Bekämpft indirekt oder direkt Glauben oder Sitte."

Die Bischöfe setzten weniger auf inhaltiche Argumentation, sondern auf mahnende Appelle an die Öffentlichkeit. In Köln ließ

20 Klaus Brüne, "Die Sünderin“ (fd 1047), in: Film-Dienst 4. Jg., Lfg. 5, 02.02.1951. 
Kardinal Frings am 4. März 1951 ein Mahnwort von den Kanzeln verlesen: "Ich erwarte, daß unsere katholischen Männer und Frauen, erst recht unsere gesunde katholische Jugend in berechtigter Empörung und in christlicher Einmütigkeit die Lichtspieltheater meidet, die unter Mißbrauch des Namens der Kunst eine Aufführung bringen, die auf eine Zersetzung der sittlichen Begriffe unseres christlichen Volkes hinauskommt. Ein Christ, der trotzdem diesen Film besucht, auch wenn er glaubt, es ohne unmittelbare Gefahr für seine persönliche Unversehrtheit tun zu können, gibt Ärgernis und macht sich mitschuldig an einer unverantwortlichen Verherrlichung des Bösen. ${ }^{21}$

Diese aus heutiger Sicht extrem einengende Position, die es selbst verbietet, sich kritisch mit dem Film auseinanderzusetzen, hatte deutlich ihre Auswirkungen und spiegelt exemplarisch eine Haltung, die auch heute noch in Reaktionen kirchlicher Gruppen auf Skandalfilme zu verzeichnen ist. Die Angst, durch einen Film einer Art Gehirnwäsche unterzogen zu werden, spricht noch aus den Protesten zum letzten großen Skandalfilm „Die letzte Versuchung Christi".

Zur Verdeutlichung der Haltung, die die katholische Hierarchie vertrat, ist der Hirtenbrief der deutschen Bischöfe zur Filmfrage aufschlußreich, der erst nach dem Skandalfall veröffentlicht wurde, aber durch die Erfahrungen auch mit diesem Film geprägt ist ${ }^{22}$. Zwar werden - darin der Enzyklika "Vigilanti Cura" folgend - die positiven Möglichkeiten ausdrücklich gewürdigt (,Eine Reihe guter Filme zeigte die großen Möglichkeiten, die der Film zur echten Menschenbildung besitzt." (53), der Anlaß für den Hirtenbrief ist jedoch das große "Aber", das danach folgt: der Film als Instrument der "gottlosen Absichten“ (54) des bösen Feindes. Dabei wird deutlich, daß Gewaltfilme - erwähnt wird die „wahre Flut von Kriminalfilmen" (54) -, aber auch Filme wie die nicht explizit erwähnte "Sünderin“ als Sabotage an der Aufbauarbeit verstanden wurden: „Während in allen Teilen unserer Heimat verantwortungsbewußte Männer und Frauen ihre ganze Kraft für den materiellen und seelischen Wiederaufbau einsetzten, liefen in zahlreichen deutschen Kinos Filme, die dem gesunden menschlichen Empfinden, den Forderungen der natürlichen Sittlichkeit und den Grundsätzen des christlichen Gewissens widersprachen." (54) Die Unsicherheit in bezug auf die sittliche Festigkeit der Menschen hat für die Bischöfe einen ganz konkreten Hintergrund in den Erfahrungen der unmittelbaren Nachkriegszeit: „Wie verheerend die Mißachtung der Frauenwürde, die Verherrlichung der freien Liebe und des Ehebruchs sich gerade in der Verwirrung der Nachkriegsjahre ausgewirkt haben, ist uns allen offenbar." (54) Das Hirtenwort setzt das fort, was in der "Sünderin"-Debatte eine Rolle spielte: Es appelliert an alle Verantwortli-

21 Zit.n. "Kardinal Frings zur ,Sünderin“" in: Film-Dienst 4. Jg., Lfg. 10, 09.03.1951, 1 .

22 "Das Hirtenwort des deutschen Episkopats zur Filmfrage", zit.n. Dokumente Katholischer Filmarbeit, a.a.O., 53-57, hier: 54. 
chen in der Filmwirtschaft und fordert das "ganze katholische Volk" auf, sich $\mathrm{zu}$ informieren und speziell die mit " $3^{\prime \prime}$ oder " ${ }^{\prime \prime}$ eingestuften Filme nicht zu besuchen. "Ihr wißt nicht, ob ein solcher Film für Euch nicht nächste Gelegenheit zur Sünde werden kann.“" (56)

Hierarchie wie Basis waren sich in der Ablehnung der "Sünderin" einig. An vielen Orten gab es spontane Aktionen: Protestmärsche, Schweigemärsche, Bußwallfahrten bis zu gewaltsamen Aktionen vom Zerschlagen von Schaukästen bis zu Niespulver und Stinkbomben im Kino. Im Umfeld dieser Aktionen waren die in Düsseldorf gestarteten Aktionen des Pfarrers Dr. Carl Klinkhammer die bekanntesten. Klinkhammer arbeitete in enger Zusammenarbeit mit dem CDU-Oberbürgermeister Gockeln, der - wie Klinkhammer in einem Fernsehinterview bekannte - sogar die Anregung zu den organisierten Protesten gab ${ }^{23}$.

Die organisierten Protestaktionen, die sich aus allen Teilen der katholischen Bevölkerung rekrutierten, hatten Symptome eines Kulturkampfes: „Zum erstenmal seit dem Kampf um die Konfessionsschule gab es eine geschlossene katholische Meinung im kulturpolitischen Raum."24 Ziel der Aktionen war die Artikulation eines Unmuts, mit der Schaffung eines Tatbestandes nach \$14 des Polizeiverwaltungsgesetzes, nach dem ein Verbot erteilt werden konnte, wenn der Film zur öffentlichen Unruhe geführt hatte. In einzelnen Städten, z.B. in Koblenz, Freising, Regensburg, wurde der Film auch nach Aktionen tatsächlich polizeilich verboten.

Der Skandal um "Die Sünderin" hatte konkrete Folgen: für das Rechtssystem war bedeutsam, daß die Polizeizensur abgeschafft wurde, für die filmpolitischen Ziele der Kirchen war ein Erfolg, daß die FSK im Sinne der Kirchen reformiert wurde, so daß ein Gleichgewicht zwischen den Vertretern der Filmwirtschaft und denen der Öffentlichen Hand hergestellt wurde. Außerdem führte die erfolgreiche Mobilisierung der Basis zur Gründung der Katholischen Filmliga, die schon die päpstliche Enzyklika empfohlen hatte und deren Mitglieder sich durch ein freiwilliges Versprechen verpflichteten, schlechte Filme $\mathrm{zu}$ meiden und gute durch ihren Besuch zu fördern ${ }^{25}$. Die Basis stand im Vordergrund, denn - so Dir. Kochs - die "Kirche ist nicht eine kleine Zahl von Bischöfen und Pfarrern, die dann eine mehr oder weniger gehorsame Herde von Schäflein mit Kommandoworten zu regieren hätten"26. Die Filmliga wurde gegründet mit dem Anspruch, "die positiven Bewegungen in den Vordergrund [zu] stellen" (ebd.), auch wenn die Filmwirtschaft, die die Auswirkungen eines Boykotts durch katholische Zu-

23 Klinkhammer in einer Sendung des WDR-Fernsehen "Rückblende: "Die Sünderin 1951". Streit um die Filmfreiheit" von Henning Burk, WDR 1986. Brüne, „Die Sünderin". Zwölf Monate später, o.S.

25 Vgl. Bettecken, a.a.O., 28ff.

26 Anton Kochs, „Die Kirche an die Filmwirtschaft", in: Film-Dienst 4. Jg., Lfg. $15,20.04 .1951$, o.S. 
schauerkreise deutlich zu spüren bekam, die negativen Seiten hervorhob und gegen die "kirchliche Nebenzensur" polemisierte und rechtliche Schritte erwog 27 .

\section{Streit um religiöse Filme}

Die Erfahrungen mit der "Sünderin“ änderten an der im Kern positiven Einschätzung der Möglichkeiten des Films nichts. So unterstrich Dir. Anton Kochs in einer Rede auf dem Internationalen Farbfilmkongreß in Köln am 17.04.1951:"Die Kirche bejaht den guten Film. Sie erkennt in ihm eine wundervolle Schöpfung des von Gott geschaffenen Menschengeistes, der vielleicht sogar fähig ist, das menschliche Wort im Ausdruck göttlicher Dinge zu unterstützen [...]. ${ }^{\prime 28}$

In der oben erwähnten Ansprache von Dir. Kochs wird auf ein besonderes Kapitel umstrittener Filme hingewiesen, das meist übersehen wird. "Sie werden, wenn Sie aufmerksam waren, bemerkt haben," erläutert Kochs, „daß wir in unserem Urteil über die künstlerische Gestaltung im eigenen Lager besonders streng waren. Wir stehen gerade in Überlegungen, einen religiösen Film wegen seiner ungenügenden und fast verletzenden Gestaltung in die Gruppe $3=$ abzuraten, einzugliedern. (Nicht, wie böswillige Spötter uns nachsagten, um diesem den Kassenerfolg zu sichern, sondern um auszudrücken, daß die höchsten Ideen die besten Ausdrucksmittel verlangen.)“ (ebd.).

Die in einigen Fällen deutlich ablehnende Haltung gegenüber Filmen mit religiösen Inhalten hatten zum Teil weiterreichende Konsequenzen als die Proteste gegen Filme wie "Die Sünderin". Zwei Fälle sind hier für die 50er Jahre vor allem zu nennen, beides italienische Produktionen. Der Film "Antonius von Padua" (1949) hatte in der Originalfassung der Kirchlichen Hauptstelle vorgelegen und eine allgemeine Empfehlung bekommen. Der in der Verleihfassung vorgelegte Film erhielt von der Filmkommission aufgrund seiner oberflächlichen Machart und der mangelhaften österreichischen Synchronisation nur die Note "2J" = ,auch für Jugendliche, ab etwa 16 Jahren". Der Inhaber des Diamant-Filmverleihs versuchte daraufhin, nachdem er in Konkurs gegangen war, einen Prozeß gegen die Kirche zu führen, weil er glaubte, durch die schlechte Einstufung sei sein Geschäft verdorben worden. So strengte er eine Klage gegen den Erzbischof von München, Kardinal Wendel, an, die aber keinen Erfolg hatte. „Filmverleih verklagt Erzbischof" war immerhin eine Schlagzeile der Boulevardpresse ${ }^{29}$.

Die Produktion „Der Sohn Gottes" (Il figlio dell'uomo/1955) war

$\overline{27}$ Vgl. Bettecken, a.a.O., 20ff.

28 Kochs, „Die Kirche an die Filmwirtschaft", a.a.O., o.S.

29 Vgl.: "Zum angekündigten Prozeß gegen Kardinal Wendel", in: Film-Dienst 7. Jg., Lfg. 16, 16.04.1954, o.S. 
eine kirchliche Produktion. Produzent war die Sanpaolo-Filmgesellschaft, die Produktionsgesellschaft der Pia Società San Paolo in Rom. In Italien war der Film für alle Altersstufen und speziell für Pfarrkinos empfohlen worden. Der Sekretär der Päpstlichen Kommission für Film, Funk und Fernsehen hatte sich persönlich an Direktor Kochs gewandt, der daraufhin die deutsche Synchronisation betreute. Die Filmkommission kam bei ihrer Sichtung zu dem Ergebnis, der Film sei aufgrund der oberflächlichen Machart, aufgrund der Klischeehaftigkeit und Abweichungen von der Bibel mit " $3^{\prime \prime}=$ "Abzuraten" einzustufen. Der Überprüfungsausschuß, dessen Einberufung der Verleih beantragt hatte, kam zu demselben Ergebnis. Aufgrund eines Einspruchs des Verleihs beim damaligen Filmbischof Dr. Leiprecht, Rottenburg, wurde erstmals ein letztinstanzlicher Oberausschuß, besetzt mit vier Geistlichen und drei Laien, einberufen, der im Juli 1957 abermals das Urteil bestätigte.

Gerade an diesen und ähnlichen Fällen zeigte sich, daß die strikte Trennung von formaler Beurteilung und sittlich-moralischer Bewertung problematisch ist, wie sie noch zu Beginn der 50er Jahre gegolten hatte. Eine zunehmende Diskussion wird spätestens seit Mitte der 50er Jahre zunehmend spürbar. In Lfg. 21, 26.05.1955 läuft unter dem Kürzel „A.“30 ein Leitartikel zum Begriff des sittlichen Urteils. Darin heißt es: „Ein Film also, der die Wirklichkeit des Lebens mißachtet, kann trotz unablässiger ethischer Reden, trotz einer formellen Unanfechtbarkeit der Handlung nicht im Tiefsten sittlich sein. Denn das Sittliche ist kein bloßes Abstraktum, es steht in enger Beziehung zum Leben, das es ja sinnvoll ordnen soll, und wer das Leben verfehlt, muß notwendig auch die ordnende Kraft des Lebens verfehlen. Daher ist es selbstverständlich, daß sich das sittliche Urteil nicht vom Problem der Gestaltung trennen läßt." 31 In besonderer Weise ist dies bezogen auch auf die religiösen Filme, die Anlaß zu Ablehnung waren: „Es kann nicht Aufgabe kirchlicher Stellen sein, in der Gestaltung mißratene religiöse Filme oder freundlich verfilmte sentimentale Geschichten zu empfehlen, in denen man im Traktatstil vom lieben Gott redet." (ebd.)

\section{Filmkommission gegen Amtskirche: „Das Schweigen“ (1963)}

Spiegelt sich in den 50er Jahren wie in dem zuletzt erwähnten Leitartikel ein Bewußtsein für die notwendige Komplexität einer Filmbeurteilung aus christlicher Sicht, die die formale wie inhaltliche Seite gleichermaßen berücksichtigt, wird der Wandel am größten Skandalfall der 60er Jahren, an der Auseinandersetzung um Ingmar Bergmans "Das Schweigen" konkret sichtbar.

30 Hinter dem Pseudonym „A." verbarg sich Dr. Theo Fürstenau, der damalige Vertreter des Bundes bei der FSK.

31 A., "Das sittliche Urteil", in: Film-Dienst 8. Jg., Lfg. 21, 26.05.1955, 1. 
Die 60er Jahre sind eine entscheidende Epoche im politischgesellschaftlichen Wandel ebenso wie in der kirchenpolitischen Neudefinierung des Verhältnisses zur Welt. In gleicher Weise sind die 60er Jahre ein Jahrzehnt der filmästhetischen Innovationen, der ,neuen Wellen'. Der Filmhistoriker Ulich Gregor unterstreicht den deutlichen Neuanfang und betont, daß "die beginnenden sechziger Jahre den plötzlichen Aufbruch vielfältiger neuer Impulse, neuer nationaler Filmbewegungen" mit sich brachten und durch neue Generationen junger Regisseure, die sich in Bewegungen wie der Nouvelle Vague in Frankreich, dem brasilianischen Cinema novo oder dem Jungen deutschen Film zusammenschlossen, "die internationale Filmszene eine qualitative Veränderung erfuhr “32. Mit den neuen Wellen und dem zunehmenden Bewußtsein für neue Formen setzt sich auch die Autorentheorie durch, die das Einzelwerk in den Kontext des Gesamtwerkes eines Regisseurs, der als wesentlicher Urheber des Filmkunstwerks betrachtet wird, einordnet.

"Das Schweigen" steht in einem Kontext anderer religiös relevanter Filme in den 60er Jahren. Zunehmend wurde eine religions- und kirchenkritische Haltung erkennbar. Dabei war es nicht in erster Linie die Generation der jungen Filmautoren, die das Jahrzehnt geprägt hat. In Schweden schuf Ingmar Bergman seine Trilogie "Wie in einem Spiegel" (1960), "Licht im Winter" (1961) und "Das Schweigen" (1963), in denen die zunehmende Krise einer Gesellschaft, die in der Erfahrung eines schweigenden Gottes lebt, mit aller Schärfe artikuliert wird. Luis Buñuel stellte die christliche Praxis auf die Nagelprobe in "Viridiana" (1961) oder kritisierte die Kirchengeschichte als sinnlosen Streit um Dogmen in "Die Milchstraße" (1969). Der wichtigste Vertreter des neuen europäischen Autorenkinos, das in den 60er Jahren stark wurde, ist mit Blick auf den religiösen Film ohne Zweifel Pier Paolo Pasolini, dessen Filme „La Ricotta/Der Weichkäse" (1962) und „Teorema“ (1968) heftig umstritten waren, wobei der erste Film dem Autor im ersten Fall sogar eine Haftstrafe wegen Blasphemie einbrachte. Im Zeichen des Kalten Krieges stellten Filme aus Ostblockländern ein besonderes Problem dar. Es gab einen Interministeriellen Ausschuß, der Filme prüfte und ggf. ein Einfuhrverbot aussprechen konnte. Der bekannteste Fall ist der polnische Film "Mutter Johanna von den Engeln" (1960) von Jerzy Kawalerowicz, der als atheistische Propaganda gedeutet wurde 33 .

Die Kirchen gerieten in das Kreuzfeuer der Kritik, weil man ihnen Zensurbestrebungen vorwarf. Kontakte der Kirchenvertreter zu Verleihern, die bestrebt waren, Filme in einer Fassung zu präsentieren, die

32 Ulrich Gregor, Geschichte des Films ab 1960. (Bd. 3 der "Geschichte des Films", Taschenbuchausgabe) Reinbek bei Hamburg 1983, 9; zuerst München 1978.

33 "I,Mutter Johanna, - Legende und Wirklichkeit", in: film-dienst 17. Jg., Nr. $22,03.06 .1964,1-3$. 
nicht mit Kritik von seiten der Kirche zu rechnen hatte, führten zu Sichtungen und Einflußnahmen auf Schnitt und Synchronisation. Die linksliberale Filmkritik, die sich um die einflußreiche Zeitschrift "Filmkritik" gesammelt hatte, beschwor die Gefahr, man stehe "unmittelbar vor der Etablierung einer katholischen Filmzensur"

War „Die Sünderin“ der meistdiskutierte Skandalfilm der 50er Jahre, so steht $\mathrm{ihm}$ in den 60er Jahren als ähnlich herausragendes Beispiel nur Bergmans „Das Schweigen“ gegenüber. Wie bei keinem anderen Film schlugen hier die Wellen der Empörung hoch. Dennoch ist dieser Film aus der Sicht katholischer Filmkritik völlig anders zu bewerten, weil in diesem Fall die Fronten anders verliefen. Die Beurteilung des Films durch die Experten in verschiedenen Gremien schien zunächst fast problemlos. Zwar erkannte man die Schwierigkeiten, aber würdigte den künstlerischen Rang. Die FSK gab den Film für Jugendliche ab 18 Jahren am 10.12.1963 frei. An der Entscheidung hatte der Beauftragte der evangelischen Kirche mitgewirkt, da zur damaligen Zeit immer nur ein Kirchenvertreter im Wechsel tätig war. Berichte und Gerüchte über heftige Kontroversen zwischen evangelischen und katholischen Kirchenvertretern sind frei erfunden. Am 18.12.1963 erhielt der Film in der FBW das Prädikat "besonders wertvoll“. In einer ausführlichen Begründung würdigte der Auschuß die künstlerische Qualität.

Schon in der Ausgabe vom 04.12.1963 hatte sich der "film-dienst" mit Bergman ausführlich beschäftigt. Im Leitartikel schreibt der Mitarbeiter Martin Ripkens: „Der fünfundzwanzigste Film des fünfundvierzigjährigen Ingmar Bergman, ,Das Schweigen', ist ein Skandal. Er ist es nicht wegen dreier bestimmter Szenen. Er ist es seinem ganzen Thema nach. Bergman konfrontiert [...].den Betrachter erbarmungslos mit einer Wahrheit, die eine sehr persönliche Wahrheit ist. Sie widersetzt sich jeder wissenschaftlichen Erfahrbarkeit. Niemand muß diese Wahrheit annehmen, doch auch wer Bergmans Bekenntnis nicht zu teilen vermag, wird sich dem Ernst und der Aufrichtigkeit seiner Anfrage nicht entziehen können. Wenn Gott schweigt, wird die Welt zur Hölle, sagt Ingmar Bergman. Er zeigt es, unverstellt, und das ist es, was Christen wie Atheisten betroffen macht. Das ist der Skandal." 35 Dieselbe Ausgabe enthält die bis dahin umfangreichste Darstellung des Werkes eines Regisseurs. P. Joseph Burvenich S.J. (Brüssel), ein Bergman-Kenner, stellt den künstlerischen Rang des "Schweigens" ebenso deutlich heraus wie der Leitartikler: „Es ist ein Film voller Schönheit, sehr gewagt und - wie ich meine - hinsichtlich der Absichten

${ }_{34}$ Wolf Götz (gtz), "Schneiden für die Kirche”, in: Filmkritik 6. Jg., H. 1/1962, 1.

35 Martin Ripkens, "Bergmans Hölle", in: Film-Dienst 16. Jg., Lfg. 49, $04.12 .1963,481 f$. 
des Autors und der Darsteller ehrlich und rein. “36 Aber der Autor stellt auch Fragen, die die folgende Diskussion bestimmen werden: „Ist der Film das passende Mittel für einen Künstler, wie Bergman es unbestreitbar ist, sich von quälenden Gedanken und Vorstellungen, die er mit vielen anderen Menschen gemein hat, $\mathrm{zu}$ befreien? Ist der Film nicht vor allem eine soziale Kunst', welche nicht leben kann ohne die Masse, die auf Schocks, wie sie von manchen Szenen und Situationen in solchen Filmen ausgehen, kaum vorbereitet ist?" (ebd.)

Am 23.12.1963 sichteten zehn Mitglieder der Katholischen Filmkommission den Film in Düsseldorf ${ }^{37}$. Das Ergebnis der Diskussion ergab die Einstufung "2EE“ = "Für Erwachsene mit erheblichen Einwänden“. Die Wertung findet ihren Niederschlag in der ausführlichen "film-dienst"-Kritik von Franz Everschor, die nicht mehr allein nach der moralisch-sittlichen Bewertung der gezeigten Handlungen fragt, sondern die Gesamtdeutung auch in der Form sucht, zu deren Interpretation das Gesamtwerk des Regisseurs herangezogen wird. Everschor kommt zusammenfassend zu dem Schluß, der Film könne eine „heilsame Konfrontierung mit Dingen, die unserer Welt, die uns selbst immanent sind“38 sein: "Der Schock, die Provokation, der Skandal dieses Films rütteln wach, auch den, der vielleicht aus falscher Spekulation ins Kino geraten ist. Die Sinnlosigkeit solchen Lebens, der Ekel vor diesem unwürdigen Dasein, die Abwesenheit jeder Erfüllung und jedes Zieles in der verlassenen Welt fordern Gott. Bergman gibt keine Antwort. Aber er entläßt den Zuschauer mit einer Frage, einem Schrei." (ebd.) Während Everschor unterstellt, der Film könne seine Botschaft gerade auch jenen Zuschauern vermitteln, die aus Sensationsgier gekommen sind, schränkt das Kommissionsgutachten deutlicher ein: „Der Film eignet sich [...] ausschließlich für reife Erwachsene." (ebd.)

Die einheitliche Front von Amtskirche, Katholischer Filmkommission und Basis gab es beim "Schweigen" nicht mehr. Die Fronten verliefen hier auch innerhalb der Kirche und sogar innerhalb der Filmkommission. Schwierigkeiten zeichneten sich ab in einer Meinungsverschiedenheit zwischen der Filmkommission und ihrem Vorsitzenden. Dir. Kochs eröffnete nach eigener Sichtung ein Überprüfungsverfahren, das am 02.02.1964 stattfand mit 23 stimmberechtigten Mitgliedern und ca. 20 Gästen. Nach heftiger Diskussion wurde die erforderliche 2/3 Mehrheit für eine Änderung der Einstufung nicht erreicht. Die auf Antrag von Kochs einberufene dritte Instanz, der Oberausschuß der

36 Joseph Burvenich, „Ingmar Bergman auf der Suche nach dem Sinn des Lebens"، Beilage zum Film-Dienst 16. Jg., Lfg. 49, 04.12.1963, o.S.

37 Zu den Vorgängen vgl. die Darstellung von Dir Kochs im Rundbrief Nr. 1/1964, an alle Diözesanstellen der Film- und Fernsehliga, an die Diözesanfilmstellen und an die Mitarbeiter (28.02.1964).

38 Franz Everschor, „Das Schweigen” (fd 12486), in: film-dienst 17. Jg., Nr. 2, 15.01.1964, o.S. 
Katholischen Filmkommission, besetzt mit sieben ausgewiesenen Vertretern der Pastoral, speziell Moraltheologen, brachte die nochmalige Bestätigung der Einstufung „2EE“.

Daß die Filmkommission ihre Einstufung des Films in allen drei Instanzen bestätigen konnte, beweist ihre Souveränität nicht nur gegenüber dem eigenen Vorsitzenden, sondern auch gegenüber deutlichen Stimmen aus der Amtskirche. So hatte z.B. das Generalvikariat Köln eindringlich vor dem Besuch gewarnt und erklärt, auf den Film seien die üblichen Noten nicht anwendbar. ${ }^{39}$ Ein Skandalfilm erhielt von der Filmkommission kein "Abzuraten". Allerdings wurde in den Kommentierungen die Kommissionsentscheidung doch noch auf ein "Abzuraten" hin verschoben. Im Leitartikel des "film-dienstes" vom 26.2.1964 wird die Bedeutung der Wertungsnote 2EE erläutert und mit einer deutlichen Warnung verbunden: „2EE-Filme fordern nach Ansicht der Katholischen Filmkommission erheblichen Widerspruch heraus; sie verlangen vom Zuschauer eine Urteilsreife, die das Durchschnittspublikum im allgemeinen vermissen läßt, [...]. 2EE ist kein Freibrief für einen harmlosen Erwachsenenfilm, sondern heißt: Vorsicht, Fußangeln!"40 Noch deutlicher wird der Oberausschuß in seiner veröffentlichten Stellungnahme, die die religiös-theologische Interpretation als nicht zwingend einstuft und die Warnung verschärft, daß der Film ein Trauma auslösen, durch die seelische Belastung eine gesunde Einstellung zur geschlechtlichen Partnerschaft und Ehe gefährden könne ${ }^{41}$. Schließlich formulierte eine auf der Jahrestagung der Katholischen Filmarbeit in Trier (31.03.-02.04.1964) verabschiedete Resolution nochmals den "dringenden Rat, den Film ,Das Schweigen" nicht zu besuchen und sich den von diesem Film ausgehenden schweren Belastungen nicht auszusetzen. ${ }^{\prime 42}$

Von den potentiellen positiven Wirkungen des Films, die noch der Kritiker Everschor festgestellt hat, ist zunehmend weniger die Rede. Dennoch zeigt die Debatte um den Film, daß die katholische Filmkritik differenziert mit den inhaltlichen wie formalen Aspekten umzugehen versteht. Daß der Film nicht formell als „abzuraten“ eingestuft wurde, ist auf die Einschätzung des künstlerischen Wertes zurückzuführen, aber auch sicherlich mitbeeinflußt durch die strategische Überlegung, $\mathrm{daß}$ eine totale Ablehnung auch eine publizistisch werbewirksame Vermarktung einschloß. Die in ihren moralisch rigorosen Urteilen harschen Verrisse des "film-dienstes", die mit einem apodiktischen

39 Vgl. „Generalvikariat warnt vor Bergman-Film“ (KNA-Meldung), zit.n. Gert $\mathrm{H}$. Theunissen, Das Schweigen und sein Publikum. Eine Dokumentation, Köln/Duisburg 1964, 20.

40 „Was heißt eigentlich 2EE?", in: film-dienst 17. Jg., Nr. 8, 26.02.1964, 1 f.

41 Zit.n. Anton Kochs, "Resümee über ,Das Schweigen" „in: film-dienst 17. Jg., Nr. 10, 11.03.1964, 1f.

42 Zit.n. "Erklärung über "Das Schweigen" " in: film-dienst 17. Jg., Nr. 14, 08.04.1964, o.S. 
"Abzuraten" endeten, hatten für manche Kinobesucher - wie sich der Filmwissenschaftler Hans Helmut Prinzler erinnert - auch einen Reiz, sie gehörten „zur Vorlust auf das Kino“43.

Die professionelle katholische Filmkritik stand nicht nur unter innerkirchlicher Kritik, sondern vertrat eine Position, die auch in der säkularen Presse auf das Heftigste umstritten war. Günther Engels verriß den Film aufgrund jener Szenen, „die mit aller Deutlichkeit Dinge auf die Leinwand bringen, die man bislang allenfalls delikat angedeutet sah: Die Selbstbefriedigung einer Lesbierin und die schamlose Paarung eines Pärchens in der Loge eines Variétés." ${ }^{44}$ Noch mehr war er über "das Versagen kirchlicher Kultur-Experten" entsetzt: „Der katholische "Filmdienst ${ }^{3}$, der gemeinhin pingelig mit der Lupe nach Unziemlichkeiten äugt, gerät in eine metaphysische Verzückung, zu der kein Wort, kein Bild und kein Sinnbild in dem Film ernsthaft Anlaß geben." (84)

Auch diejenigen, die wie der "film-dienst" die religiösen Bezüge anerkannten, stellten die Frage nach der ästhetischen Kompetenz des Zuschauers. Rainer Fabian artikulierte im "Rheinischen Merkur" die vielfach geäußerten Zweifel, ob die theologisch relevanten Bezüge überhaupt wahrgenommen werden: „Den ,Schrei nach Gott”, mit dem der Filmbesucher aus dem Kino entlassen werden soll, fühlt nur jener, der die Bildsprache $\mathrm{zu}$ dechiffrieren vermag. Tatsache jedoch ist, daß das Millionen-Publikum den artifiziellen Teil (die Scheinwirklichkeit) mißverstehen wird, während es die naturalistisch gezeigten PaarungsSzenen in gewöhnlicher Seh-Manier aufsaugt und als platte Wirklichkeit empfindet." 45

Die Debatte verschob sich über den konkreten Film hinaus zu einer generellen Frage nach der Bedeutung von Bergman. Die Befürworter des Films argumentierten in erster Linie von Bergmans bis dahin veröffentlichtem Werk aus, sahen eine religiöse Relevanz, während die Gegner mitunter in einer heftigen Reaktion z.T. den Regisseur generell abwerteten, so z.B. Marcel Reich-Ranicki in der ZEIT mit der Formulierung seines Protests "gegen die deutsche Bergmanie. Man will aus diesem Regisseur einen Heiligen machen, einen Gottsucher, einen Seher, einen Propheten." 46

43 Hans Helmut Prinzler, „Shadows of the Past. Die bundesdeutsche Filmkritik der fünfziger Jahre", in: Norbert Grob, Karl Prümm (Hg.): Die Macht der Filmkritik. Positionen und Kontroversen. Literatur und andere Künste (Bd. 6), München 1990, 46-62, hier: 57.

44 Günther Engels, "Hier hört das Schweigen auf", in: Kölnische Rundschau, 29.02.1964, zit.n. Theunissen, a.a.O., 81-85, hier: 82.

45 Rainer Fabian, "Diskussion um „Das Schweigen”, in: Rheinischer Merkur, 07.02.1964, zit.n. Theunissen, a.a.O., 88-93, hier: 93.

46 Marcel Reich-Ranicki, "Der Heilige und seine Narren", in: DIE ZEIT, 27.03.1964, zit.n. Theunissen, a.a.O., 113-116, hier: 116. 
Neben der öffentlichen Debatte unter Kritikern und Kirchenvertretern gab es auch spontane Aktionen gegen den Film. Gegen den Atlas-Filmverleih wurden auch mehrere Klagen angestrengt, die aber keinen Erfolg hatten. Eine Reaktion auf die Vorwürfe führte dazu, daß Atlas dem Film einen Rolltitel voranstellte, der die theologischen Bezüge der Trilogie unter Rückgriff auf Formulierungen des „film-dienst"-Beitrags von Martin Ripkens erläuterte ${ }^{47}$.

Bei der Auseinandersetzung um Ingmar Bergmans „Das Schweigen" zeigt sich bereits, daß die katholische Filmkritik ein differenziertes Instrumentarium zur Beschreibung komplexer Filme gewonnen hat. Die Beharrlichkeit, mit der die Katholische Filmkommission trotz erheblicher Diskussionen bei der Einstufung "2EE" blieb, beweist ihre Unabhängigkeit gegenüber der Hierarchie.

\section{Filmbewertung auf dem Prüfstand: „Teorema”}

Mit dem "Fall Teorema" hat die katholische Filmarbeit auch ihre ganz eigene "68er Erfahrung“. Ohne öffentliche Aktionen wie beim "Schweigen", aber von wesentlicher Bedeutung für die Entwicklung katholischer Filmarbeit war die Debatte um Pier Paolo Pasolinis Film. Der Skandal entzündete sich an der Auszeichnung des Films auf den 29. Internationalen Filmfestpielen in Venedig, Anfang September 1968. Mit Mehrheitsbeschluß hatte die OCIC-Jury unter der Präsidentschaft des kanadischen Jesuitenprofessors P. Marc Gervais dem Film, der in parabolischer Form die Frage nach den Möglichkeiten religiöser Erfahrung in der Geschichte einer Industriellen-Familie aufzeigt, die mit einem göttlichen Gast konfrontiert wird, der in ihr Leben eingreift, den katholischen Preis gegeben. Zur Begründung sagte die Jury: „Mehr als jeder andere bei diesem Festival gezeigte Film ist dieses Werk durchdrungen von der beunruhigenden Vieldeutigkeit, die unsere Zeit in erschütternder Weise kennzeichnet, und er konfrontiert in großer Aufrichtigkeit und mitreißender, dramatischer Kraft eine gewisse bürgerliche Gesellschaft, die in ihrer ganzen Armseligkeit gezeigt wird,

47 Der Rolltitel hatte folgenden Text. „Dieser Film ist ein Skandal. Nicht, weil der Zuschauer zum Zeugen sexueller Exzesse wird. Ingmar Bergman geht es nicht um körperliche, sondern um seelische Nacktheit. „Das Schweigen” ist das Ende und der Höhepunkt einer Trilogie, die um das Gespräch des Menschen mit seinem Schöpfer kreist. "Wie in einem Spiegel" weiß noch eine Antwort: Gott ist die Liebe. „Licht im Winter" berichtete bereits von einem Pfarrer, dem Gott seine Gnade entzieht. „Das Schweigen” endlich konfrontiert uns radikal mit einer Welt, die keinen Gott mehr kennt, in der es also auch kein menschenwürdiges Dasein mehr gibt. Eine Welt, auf der das Schweigen Gottes lastet, so sagt Ingmar Bergman, wird zur Hölle. das ist der eigentliche Skandal. Das ist es, was den Film zur Herausforderung macht, - für den Christen ebenso wie für den Atheisten." 
mit einer Erfahrung, die man religiös nennen kann."48 Als der Film in Rom anlief, wurde er beschlagnahmt unter Anklage öffentlicher Verletzung der Sittlichkeit, die Klage wurde jedoch vom Gerichtshof in Venedig in der Sitzung vom 23.11.1968 abgewiesen ${ }^{49}$.

Der Skandal spielte sich zunächst auf der Ebene der OCIC ab. Der damalige OCIC-Präsident Msgr. Jean Bernard hatte eine Erklärung vorbereitet, in der er sein Bedauern über die Entscheidung der OCIC-Jury zum Ausdruck brachte und die Offenheit des Films als Gefahr einstufte: „Ohne den ästhetischen Wert des Films zu verkennen, ohne die Aufrichtigkeit des Autors in seiner Suche nach dem Spirituellen in Frage zu stellen, glaube ich doch, daß der Film in seiner Handlung sich auf Bahnen bewegt, die zur christlichen Lehre und Moral in Widerspruch stehen, und daß die Aussage in gefährlicher Weise unklar bleibt."50 Die Argumentation erinnert an die Debatte um Bergmans Film: Die Wirkung des Films wird im wesentlichen an den sexuellen Motiven festgemacht, die gerade wegen der ästhetischen Komplexität als besonders problematisch erscheinen: „Im übrigen wird die schwierige Sprache des Autors dem normalen Filmbesucher unverständlich bleiben, so daß die Gefahr besteht, bei der verwirrenden Erotik einiger Szenen stehen $\mathrm{zu}$ bleiben, die die Gefühle eines christlichen Publikums aufs gröbste verletzen.“ (43f.)

Die "Teorema"-Debatte führte zu einer harschen Kritik des Vatikans am OCIC, das zeitweise von der Auflösung bedroht war. In Deutschland schlug der Film in der Öffentlichkeit keine hohen Wellen, aber er markiert für die katholische Filmkritik einen entscheidenden Wendepunkt. Der damals Verantwortliche Redakteur des "film-dienstes", Alfred Paffenholz, wies darauf hin, daß die Pasolini-Auszeichnung in der katholischen Filmarbeit in Deutschland direkt in eine Phase der neu entfachten Diskussion um eine Änderung der geltenden Filmbewertungspraxis fiel ${ }^{51}$. Auf einer Arbeitstagung der Katholischen Filmkommission in Köln (28./29.09.1968) wurde eine Erklärung verabschiedet, in der eine Änderung der Bewertungspraxis befürwortet wurde. Darin heißt es: „Die von der katholischen Filmkommission vorgeschlagenen Änderungen sollen noch stärker als bisher den erwachsenen Zuschauer zum Dialogpartner machen, ihn zur Auseinandersetzung mit dem Film ermuntern und zur eigenen Urteilsbildung anleiten. Damit möchte die Katholische Filmkommission für Deutsch-

48 Zit.n. Yves Périgny, „Der Fall ,Teorema“" in: Communicatio Socialis 2. Jg. 1969, 41-43, hier: 41 .

49 Vgl. ebd., 43

50 Zit.n. Communicatio Socialis, 2. Jg. 1969, 43f, hier: 43.

51 Alfred Paffenholz, "Katholische Filmbewertung in der Diskussion," in: Communicatio Socialis, 2. Jg. 1969, 5-12, hier: 5f. Zum Stand der Diskussion vor ,Teorema, siehe den Bericht von Alfred Paffenholz, "Quo Vadis? Zur religiös-sittlichen Filmbewertung", in: film-dienst 21. Jg., H. 17, 23.04.1968, $1-3$. 
land dem Auftrag der Kirche, das Gespräch mit der Welt zu führen, wie es das zweite Vatikanische Konzil beschrieben hat, gerecht werden."52

Paffenholz benennt in seiner zusammenfassenden Darstellung der damaligen Diskussion um die Bewertungspraxis im einzelnen folgende Gründe für eine Kurskorrektur ${ }^{53}$ :

- Erzählweise und Bildsprache sind differenzierter geworden, es haben sich "für viele Zuschauer ungewohnte und sie strapazierende Formen der Darstellung" (7) entwickelt.

- Offenheit, Fragmentarität der Darstellung sind ein der Zeit angemessener künstlerischer Ausdrucks der Wirklichkeit: „Er [d.h. der Film] muß das Fragmentarische menschlichen Lebens als solches sichtbar machen, er muß die Bruchstellen und Gegensätze aufzeigen und darf sie nicht mit einer Scheinharmonie übertünchen.“ (7)

- Der Trend zur Enttabuisierung wird als ein "großes, legitimes Thema des modernen Films, die irritierte, rat- und rastlose Menschheit darzustellen und zur Besinnung anzuregen" (8) angesehen.

Darüber hinaus übt Paffenholz Kritik am veralteten Kunstbegriff vieler Christen: "Allzu viele Christen laufen mit einem schönfärberischen Kunstbegriff durch die Welt, mit dem man nicht mehr alle Erscheinungen unserer Welt, alle Formgesetze und entwürfe begreifen kann. Viele Christen hängen noch zu sehr der Idee von einem Kunstschutzpark an, lassen sich von Erbauungen täuschen, statt sich von der Gestaltung der Welt mit den Ausdrucksmitteln unserer Zeit ansprechen und erkenntnisreicher machen zu lassen." (8) Aber das Publikum habe sich entscheidend gewandelt. Das Kino spreche besonders die junge Generation an, die oft ein "filmgeschultes und filmbegeistertes Publikum" (ebd.) sei. Bis dahin waren die Befürchtungen immer mit Blick auf die filmunkundige Masse der sogenannten Durchschnittszuschauer ausgesprochen worden.

Als Ansprechpartner des Kritikers wird der aufgeklärte und mündige Zuschauer gesehen, und die Debatte um formale und moralisch-sittliche Bewertung ist für Paffenholz eindeutig entschieden: "Doch beim künstlerischen Film sind die formalen Elemente genauso wertbestimmend wie die thematischen." (ebd.) Daraus zieht er die Konsequenz: „Das schließt eine religiös-sittliche Bewertung zwar nicht aus, weist ihr aber für die endgültige Beurteilung eines Films einen anderen, keinesfalls dominierenden Stellenwert zu." (ebd.)

Paffenholz hatte den "film-dienst" als Verantwortlicher Redakteur bereits verlassen, als er seine Überlegungen zur Bewertungspraxis zusammenfaßte, aber die Entwicklung ging in die von ihm angedeutete

52 Zit.n. Paffenholz, "Katholische Filmbewertung in der Diskussion", 6.

53 Ebd., 7ff. 
Richtung. Die Konsequenz aus der Diskussion war letztlich, daß die Notenbewertung mit der "film-dienst"-Nr. 41/42 (1969) wegfiel.

\section{Die 70er Jahre: Skandale um Sex und Gewalt}

Die 70er Jahre sind eine - was herausragende einzelne Skandalfilme angeht - ruhigere Zeit, dennoch gibt es hier eher eine breite Welle von Problemfilmen für die kirchliche Filmkritik: Sex und Gewalt überschwemmen die Kinos. Kasse machen die Aufklärungsfilme von Oswald Kolle, die Sexfilme wie die "Schulmädchen-“ und anderen "Reports" aus diversen Berufssparten bis zu den Dirndl-Filmen eines Alois Brummer. Neben dem Sex schwappt die Welle der Gewalt in den Italo-Western voll ins deutsche Kino. Die Diskussionen bringen eine Umorientierung für die Arbeit der Freiwilligen Selbstkontrolle. Die Kirchen stellen zum 01.01.1972 ihre Mitarbeit in der Erwachsenenfreigabe im Rahmen der FSK ein und wirken seitdem nur noch bei der Jugendfreigabe mit ${ }^{54}$. Die Erwachsenenfreigabe, d.h. die Freigabe von Filmen ab 18 Jahren, wird damit in die Entscheidung der Film wirtschaft gelegt. Angesichts der Fülle der problematischen Filme richtete die Spitzenorganisation der Filmwirtschaft (SPIO) als weiteres Gremium die sogenannte Juristen-Kommission ein, die die strafrechtliche Unbedenklichkeit eines Filmes prüfen konnte. Der so mit "X $\mathrm{X}^{\prime \prime}$ gekennzeichnete Film konnte auch ohne Freigabe für Erwachsene gezeigt werden.

$\mathrm{Daß}$ Skandalfilme keine hohen Wellen mehr schlagen, hat nicht zuletzt einen Grund darin, daß das Besucherspektrum zunehmend reduziert wird. Film wird ein Freizeitvergnügen vor allem für die junge Generation von 15 bis 29. Die Filmindustrie Hollywoods begann nach dem Erfolg der ,low budget'-Produktion "Easy Rider" (1969) verstärkt, Filme für ein speziell junges Publikum zu produzieren. Im Umfeld von Pop-Musicals der Hippie-Generation wie "Hair" entstanden auch Jesusfilme mit zielgruppenspezifischer Ausrichtung: die Verfilmung der Rockopern "Jesus Christ Superstar" (1972) und "Godspell" (1973). Zwar gab es auch hier von konservativer Seite kritische Stimmen bis zu Rufen nach Verboten, aber insgesamt wurden die Filme von der katholischen Filmkritik wie auch von der Kirche insgesamt eher positiv gewürdigt. "Godspell" erhielt sogar den jährlich verliehenen Großen Preis der OCIC. Da die Kirche selbst mit Beatmessen und anderen Angeboten die Jugend erreichen wollte, kamen Versuche wie "Jesus Christ Superstar" an.

Der größte Skandalfilm der 70er Jahre ist ein Film, der noch gar nicht existierte. Über mehrere Jahre hinweg machte das Projekt des

54 Vgl. die Stellungnahme der Filmbeauftragten der evangelischen und katholischen Kirche: "Austritt der Kirchen aus der FSK", in: film-dienst 24. Jg., Nr. 21, 19.10.1971, 1 f. 
Dänen Jens Jörgen Thorsen, der durch seine Henry Miller-Verfilmung "Stille Tage in Clichy" (1969) Beachtung gefunden hatte, weltweit großen Wirbel. Es war bekannt geworden, Thorsen wolle einen Film über das angebliche Sex-Leben Jesu machen. In Deutschland wurde man durch Berichte in "Stern" und "konkret" darauf aufmerksam. Schon die Veröffentlichungen mit entsprechenden Fotos führten zu einer Rüge des Presserates. Die Deutsche Bischofskonferenz verabschiedete eine Stellungnahme gegen den Film, und der Vorsitzende der Publizistischen Kommission, Dr. Georg Moser, wandte sich 1975 noch einmal in einem Schreiben an den dänischen Botschafter, um Einspruch gegen den Film zu erheben, dem aus dem Filmförderungsprogramm der Regierung zunächst eine Unterstützung zugesagt worden war, die später zurückgezogen wurde 55 . Bis in die 80er Jahre hinein tauchten immer wieder Gerüchte auf, daß der Skandalfilm nun endlich gedreht werden sollte. Als er 1992 realisiert war, ging er schon beim dänischen Publikum sang -und klanglos unter und kam gar nicht erst nach Deutschland ${ }^{56}$.

Kurz vor dem Ende des Jahrzehnts, 1979, entstand der bis heute populärste "Skandalfilm", der 1980 auch in die deutschen Kinos kam:"Das Leben des Brian", der letzte große "Skandalfilm”, der in der katholischen Filmkritik ein „Wir raten ab" bekam. Das Kommissionsgutachten resümierte: „Eine mit krampfhaftem Klamauk und Kalauern überladene Satire auf Mißverständnisse und Fehlverhalten von Trendsetzern und ,volkstümliche' Bibelverfilmungen. Geschmacklos, zum Schluß zynisch und in manchen Szenen für Christen beleidigend. - Wir raten ab. ${ }^{\prime 57}$ Der Kritiker Leo Schönecker hatte allerdings in seiner Kritik stärker auf das formal höchst unterschiedliche Niveau hingewiesen und das Hauptaugenmerk auf die parodistische Seite gelegt: "Wer angesichts dieser Jesus-Parallele' [...] von Blasphemie und Gotteslästerung redet, hat die formal gewiß fragwürdige Satire auf menschliches und sozialpsychologisches Fehlverhalten mit allzu verkürztem Blickwinkel gesehen." (ebd.)

Die heftigste Reaktion darauf erfolgte innerhalb der Kritikerschaft. Paula Linhart, die engagierte Vertreterin kirchlicher Filmarbeit und selbst langjährige Mitarbeiterin des "film-dienstes", rügte in einem Leserbrief den unkritischen Umgang mit dem Film von seiten der christlichen Filmkritik: "Sie wirft kein kritisches Auge auf die Weise, wie hier der Stoff der Heilsgeschichte und nicht nur ein pseudoreligiöses Film-Genre gnadenlos zu einem respektlosen Filmspektakel ver-

55 Vgl. die Meldung in: film-dienst 28. Jg., Nr. 16, 05.08.1975, 6. Zur Beurteilung des Thorsen-Projekts siehe: Ambros Eichenberger, „Fragezeichen zum Projekt des dänischen ,Jesus-Films" ", in: film-dienst 29. Jg., Nr. 3, 03.02.1976, $3 f$.

56 Unter dem Originaltitel "Jesus vender tilbage" (Jesus kehrt zurück) wurde der Film von Thorsens Produktionsgesellschaft "Superfilm Productions" hergestellt.

57 Siehe die Kritik (fd 22602) in: film-dienst 33. Jg., Nr. 18, 02.09.1980, 18. 
marktet wird. Geflissentlich übersieht sie das durchgängige Assoziationsfeld, in dem der Film sein Allotria treibt, den messianischen Jesus, seine Verkündigung und seinen Tod am Galgen. ${ }^{~} 58$

Die heftigste Kritik entzündete sich an der Schlußszene. Paula Linhart: „Stellt sich nicht auch die Frage, ob wir Christen schon so weit abgestumpft sind, daß uns die makabre Formation kreuzschleppender Verurteilter nicht an den Leidensweg in der Via Dolorosa erinnert und Golgatha als lachendes Massenhenkersfeld innere Auflehnung hervorruft?" (ebd.) Die Provokation der Schlußbilder mit dem Chor der singenden Gekreuzigten ist in der Tat so überrumpelnd, daß sich auf den ersten Blick Widerspruch regen mag. Bei genauerer Analyse zeigt sich aber, daß die Blasphemie-Vermutung kaum haltbar ist. Der Text des Liedes "Always Look On the bright Side of Life“ ist eine raffinierte Konstruktion, die nicht nur als Parodie auf die am Kommerz ausgerichteten Musical-Bearbeitungen des Evangeliums funktioniert. Von der Theatrum mundi-Metapher - die ganze Welt ist eine Bühne ausgehend beschwört der Text die Unausweichlichkeit des Todes und formuliert seine scheinbar nihilistische Botschaft mit ShakespeareAnklängen (die Wortspiele mit "nothing" zitieren "King Lear"), unterstützt durch die optische Präsenz eines gähnenden Loches vor den Kreuzen, bis sich schließlich auch der Nihilismus als kommerzielles Kalkül erweist, wenn in die ausklingende Musik hinein der Hinweis ertönt, daß die Platte jetzt auf dem Markt käuflich zu erwerben sei. Man kann dem Film allenfalls vorwerfen, daß er nichts ernst nimmt, schon gar nicht sich selbst. Aus filmhistorischer Perspektive betrachtet, kann man feststellen, daß mit diesem Film der pathetische „Bibelschinken“ im Kino ein für allemal erledigt war und nur noch im Fernsehen weiterlebte. Dies wundert nicht, wenn man sieht, wie genau der Film die Schwächen der Hollywoodproduktionen bloßlegt. Schon die Anlage als Parallelhandlung ist ein Standardgriff des Bibelkinos Hollywoods, das eher von einem Centurion, einem Ben Hur oder Barrabas erzählte und die eigentliche Jesusgeschichte auf die Ebene der spiegelnden Parallelhandlung reduzierte.

Bis heute erfreut sich der Film gerade bei einem jugendlichen und studentischen Publikum besonderer Beliebtheit. Ob der religiöse Kontext daran wesentlichen Anteil hat, kann man bezweifeln, denn der Film lebt zu sehr von einer Fülle von Gags, die keinen direkten religiösen Bezug haben, sondern auf die Konfrontation zwischen leicht beschränkten Römern und den an studentische Linksaktivisten erinnernden jüdischen Revoluzzern zielen. Wie sehr die Aufregung sich gelegt hat, mag man daran ermessen, daß der Film bei zwei Ausstrahlungen im ZDF, abgesehen von einigen besorgten Anfragen, keinerlei Proteststürme mehr hervorgerufen hat.

58 Paula Linhart, "Gedanken zur Beurteilung des Films ,Das Leben des Brian“" in: film-dienst 33. Jg., Nr. 21, 15.10.1980, 5f, hier: 6. 


\section{Kunstfreiheit gegen Religionsfreiheit: „Das Gespenst” (1982)}

Die 80er Jahre sind gekennzeichnet durch drei gleichermaßen große Skandalfälle: "Das Gespenst", "Maria und Joseph" und "Die letzte Versuchung Christi". Beim "Gespenst" von Herbert Achternbusch (1982) ging es wieder einmal nicht allein um die Inhalte des Films: eine Zuspitzung erfuhr die Debatte durch die Auseinandersetzung zwischen evangelischer und katholischer Filmarbeit und die Kontroverse um die Frage der deutschen Filmförderung.

Im Arbeitsausschuß der FSK lag Achternbuschs Film am 29..03.1983 vor und erhielt keine Freigabe wegen Verstoßes gegen die FSK-Grundsätze, d.h. gegen die von der Filmwirtschaft festgelegten Normen, die einen strengeren Maßstab als die Strafgesetze freiwillig anlegen. Nach diesen Grundsätzen wurde eine Verletzung des religiösen Gefühls konstatiert und daher die Freigabe verweigert. Auf den 29. Oberhausener Westdeutschen Kurzfilmtagen verteilte die Arbeitsgemeinschaft der Filmjournalisten einen Protestaufruf, der sich gegen die Verweigerung der Freigabe richtete. Die Freigabe war für die Aufführung nicht notwendig, denn die Prüfung durch die Juristenkommission der SPIO hatte bereits ergeben, daß der Film strafrechtlich unbedenklich sei. Der Film hätte einem erwachsenen Publikum ohne weiteres vorgeführt werden können. Ohne FSK-Freigabe fehlte dem Film jedoch die wesentliche Voraussetzung zur Abnahme beim Bundesinnenminister. Achternbusch hatte für seinen Film "Das letzte Loch" den Bundesfilmpreis (Filmband in Silber) erhalten, verbunden mit einer Prämie in Höhe von $300.000 \mathrm{DM}$, die gemäß den Filmpreisrichtlinien für die Herstellung eines neuen Films zu verwenden waren. Die Zahlung der letzten Rate in Höhe von 75.000 DM stand noch aus.

Die Debatte um „Das Gespenst" spitzte sich zu, weil es eine Gegenposition auf evangelischer Seite gab. Nachdem es schon bei den Berliner Filmfestspielen Gerüchte um eine bevorstehende Auszeichnung gegeben hatte, erklärte die Jury der Evangelischen Filmarbeit Achternbuschs Werk zum "Film des Monats" April 1983. Auch wenn nach dem geänderten Statut die Auszeichnung nicht als generelle Empfehlung, sondern als Anregung zur Diskussion verstanden werden sollte, wurde dies auch in weiten Kreisen der evangelischen Kirche selbst als lobende Auszeichnung verstanden. Die Jurybegründung schlägt einen Bogen zurück zur theologischen Diskussion der letzten Jahrzehnte: "Nicht erst seit der dialektischen Theologie der 20er Jahre und der durch sie bewirkten Bewußtseinsschärfung sind scheinbar unverrückbare Begriffe wie Religion, Moral, religiöses Empfinden innerhalb der protestantischen Welt und darüber hinaus in Frage gestellt worden. "59 Dazu zählt die Jury auch Begriffe wie "religiöser Film" und den "beliebten

59 Zit.n. Film-Korrespondenz 29. Jg., Nr. 10, 10.05.1983, VII. Auch in: „Pro und contra das "Gespenst" "epd Dokumentation, Nr. 29, 20.06.1983, 9. 
Zensurbegriff ,Verletzung des religiösen Empfindens"“'. Die Stellungnahme bezieht eine grundsätzliche Position, indem sie unter Berufung auf Karl Barth feststellt: „Religiöses Empfinden - was das überhaupt sei, und $o b$ man es verletzen könne, die Antwort hängt von der selbständigen Urteilskraft des Betrachters und den ihn bestimmenden Kräften in Herkunft und Erziehung ab (vgl. hierzu auch Karl Barths Dogmatik I/2 \& 17, Religion als Unglaube)." (ebd.) Die Jury argumentiert nicht vom Inhalt des Films her, sondern vom möglichen Gebrauch. Unter Hinweis auf lohnende Diskussionen bei Pfarrer-Rüstzeiten und ähnlichen Anlässen empfiehlt sie den Film für eine Auseinandersetzung. Die Jurybegründung gipfelt in der Vermutung, das ,scheinbare Kasperlespiel“ könne "bei allen unbestreitbaren Verstößen gegen die Regeln des bürgerlichen Geschmacks in Wahrheit Antriebskräfte einer heilsamen Selbstbefragung in Gang setzen" (ebd.). Das Urteil läßt aber völlig offen, ob der Film nach Auffassung der Jury wichtige DenkanstöBe erhält, oder ob er nur einen Anlaß gibt, um über den Film hinausgehende Selbstbefragungen anzustellen.

Die Kritik im „film-dienst" von Günther Vogg bemühte sich um eine differenzierte Stellungnahme, soweit das angesichts des Films überhaupt möglich war. Vogg charakterisierte die Montage vollkommen heterogener Bestandteile als "Verschlüsselung, die sich an keine Konvention hält", demzufolge auch "nicht mehr objektivierbar und entschlüsselbar" sei, sondern allenfalls "subjektiv interpretierbar"60. Angesichts der Mischung von Zitaten und Zoten, Absurdem und Abstrusem, Hintersinn und Unsinn muß der Kritiker letztlich kapitulieren: „Ein blasphemischer Film oder ein aufrichtig-kritischer Film, ein antichristliches Pamphlet oder eine Kritik an der real existierenden Kirche, ein surreales Mysterienspiel oder absurdes Laientheater? Achternbuschs Film ist alles und nichts. “ (ebd.) Die Kritik ließ so verschiedene Lesarten offen, wenngleich sie im Abwägen von positiven und negativen Elementen zu einem eindeutigen Ergebnis kam: „Einigen eindrucksvollen Szenen und Bildeinstellungen (Schlußapotheose) stehen zahllose Geschmacklosigkeiten und Provokationen, darstellerisches Unvermögen (Novizinnen, Bischof) und quälende Längen, Klischees und Banalitäten gegenüber." (ebd.) Die Filmkommission resümierte in ihrer Stellungnahme: „Der formal mißlungene Film gefällt sich in Geschmacklosigkeiten und Provokationen, die beleidigen, weil sie das religiöse und sittliche Empfinden vieler Menschen mißachten." (ebd.) Ein "Wir raten $a b^{\prime \prime}$ wurde nicht gegeben, eher aus taktischen Gründen, um die Diskussion nicht zusätzlich anzuheizen und dem Film dadurch Publizität zu verschaffen.

Nachdem offizielle Reaktionen der Amtskirche auf katholischer Seite zunächst bewußt vermieden worden waren, gaben die verfälschen-

60 Günther Vogg, „Das Gespenst" (fd ), in: film-dienst, 36. Jg., Nr. 9, 03.05.1983, $14 f$. 
den Darstellungen über die Entscheidung des Bundesinnenministers und die Auszeichnung des Film durch die Jury der evangelischen Filmarbeit den Anlaß zu einer Äußerung des Leiters der Zentralstelle Medien, Prälat Wilhelm Schätzler61. Inzwischen war der Film im Revisionsverfahren in der FSK im Hauptausschuß mit der Begründung der Meinungsvielfalt freigegeben worden. Angesichts einer positiven Stellungnahme einer kirchlichen Jury ließ sich die Argumentation einer Verletzung religiösen Empfindens nicht mehr halten. In seiner Stellungnahme vom 28.04.1983, die zeitgleich mit der Kritik im "film-dienst" gemeldet wurde, weist Schätzler neben der Richtigstellung der Vorgänge im Rahmen der BMI-Förderung und der FSK auf die „ernste Belastung " der ökumenischen Zusammenarbeit durch die Juryentscheidung hin. Fast noch schärfer formulierte der Sprecher der EKD in einer offiziellen Stellungnahme vom 05.05.1983 das Bedauern der EKD darüber, „daß die Jury über viele Szenen hinweggesehen hat, in der die Person Jesu Christi und Symbole des christlichen Glaubens auf groteske und verletzende Weise verfremdet werden." 62 Die Jury verteidigte sich in einer Stellungnahme: „Kritikfähigkeit und Kritikbereitschaft, die Achternbuschs Film herausfordert, scheinen in Teilen der christlichen Öffentlichkeit und der Amtskirche unterentwickelt. ${ }^{163}$

Von seiten der Deutschen Bischofskonferenz gab die Publizistische Kommission am 08.07.1983 eine Stellungnahme ${ }^{64}$ ab, als Reaktion auf eine Welle von Protesten, die zum einen die Verletzung des religiösen Empfindens und zum anderen die Tatsache der Förderung des Films mit öffentlichen Mitteln betrafen. In vier thesenartigen Punkten stellt die Publizistische Kommission fest:

1. Der Film sei „eine Verunglimpfung dessen, was ihnen [den Gläubigen] heilig" sei. (ebd.)

2. Der Protest ist nicht ein Versuch, Achternbusch am Filmemachen zu hindern, sondern ein Widerspruch dagegen, "sich von Achternbusch beleidigen zu lassen" (ebd.).

3. Unter Bezugnahme auf die Verfassung wird ein individualistischer Freiheitsbegriff zurückgewiesen, der die Kunstfreiheit über alle anderen Grundrechte stellt. Dagegen wird argumentiert, daß Freiheit ohne soziale Bindung, d.h. hier speziell Rücksicht auf die Überzeugungen anderer, nicht realisiert werden kann.

4. Die Herstellung einer Öffentlichkeit durch den Film und die öffentliche Herabsetzung des religiösen Bekenntnisses der Christen wird "zum Tatbestand der Störung des öffentlichen Friedens" (ebd.). Damit wird ein direkter Bezug zum Straftatbestand des § 166 StGB hergestellt.

61 Zit.n. Film-Korrespondenz 29. Jg., Nr. 10, 10.05.1983, VlIIf;; auch in: epd Dokumentation, a.a.O., 16.

62 Zit.n. Film-Korrespondenz 29. Jg., Nr. 10, 10.05.1983, X; auch in: epdDokumentation, a.a.O., 28.

63 Zit.n. epd-Dokumentation, a.a.O., 42. 
5. Als Stellungnahme zu den Kriterien der Filmförderung wird ausdrücklich betont, daß Kriterien nicht dazu dienen dürfen, „politisch oder ästhetisch unliebsame Richtungen von der staatlichen Förderung auszuschließen“ (ebd.).

Die Diskussion um den Film lief auf verschiedenen Ebenen: Während die Befürworter des Films Karl Valentin und Luis Buñuel als Ahnherren ins Feld führten, fanden die Gegner eine oberflächliche und willkürliche Verwendung christlicher Themen und Symbole in eindeutig verletzender Absicht. Dabei spitzte sich die Diskussion zunehmend auf die Frage der künstlerischen Freiheit im Rahmen öffentlicher Filmförderung zu. Die Befürworter sahen diese durch ein Verhalten des ohnehin von vielen Filmschaffenden ungeliebten Bundesinnenministers als extrem gefährdet an, während die kirchliche Position nicht Kunstfreiheit als absoluten Selbstwert, sondern in ihrer sozialen Einbindung verstanden wissen wollte 65 . Der damalige Filmreferent in der Zentralstelle Medien, Reinhold Jacobi, wies die einseitige Betonung der künstlerischen Freiheit und die Kritik am Protest der Kirchen im Namen der betroffenen Gläubigen zurück: „Die vehementen Verfechter der Kunstfreiheit vernachlässigen - wie häufig -die Religionsfreiheit. [...] es hat sich gerade in dieser Kontroverse der Eindruck verdichtet, als halte die liberale Presse Glaubensinhalte als wesentliche Elemente der Religionsausübung für allenfalls privatistische Angelegenheiten. Den Schutz dieser Interessen haben gewissermaßen die Betroffenen selbst einzufordern. Die Kunstfreiheit dagegen: Empören und Eintreten für potentiell Betroffene allenthalben. ${ }^{\prime 66}$

Ein großer Teil der Diskussion um Inhalte drehte sich weniger um theologische Fragen als um die Verstöße gegen das Geschmacksempfinden. In dieser Hinsicht ist die Äußerung des Bundesinnenministers Zimmermann durchaus typisch, der in einem SPIEGEL-Interview bekannte: „Ich lasse nicht $\mathrm{zu}$, daß mit Steuergeldern gefördert wird, daß einem Christus am Kreuz eine Schweinszunge aus dem Munde hängt, daß Kröten gekreuzigt werden und daß besoffene Polizisten ihre Notdurft in ein Schnapsglas verrichten, während ununterbrochen auf der Polizeiwache das Telephon läutet, aber niemand hingeht, um die Assoziation zu erwecken, bei der Polizei brauchst du nicht anzurufen: Die sind besoffen, die haben für dich keine Zeit."67 Im Sinne der

65 Der Leiter der Zentralstelle Medien, Prälat Wilhelm Schätzler, griff die Argumentation noch einmal in einem Zeitungsartikel auf: „Die Freiheit von Faust und Nase", in: Rheinischer Merkur/Christ und Welt, 19.08.1983.

66 Reinhold Jacobi, „German Filmers, Angst. Zur Gegenwart und Zukunft der deutschen Filmförderung. Spätsommer 1983“, in: Film-Korrspondenz Nr. 18, 30.08.1983, 1-8, hier: 2. In diesem Beitrag findet sich auch eine umfangreiche Aufarbeitung der Pressestimmen zum Fall Achternbusch. Vgl. auch: Reinhold Jacobi, "Skandal um ein Gespenst", in: Rheinischer Merkur/Christ und Welt, Nr. 17, 29.04.1983.

67 "Alles zusammen ergibt einen Kurs," SPIEGEL-Gespräch, in: DER SPIEGEL, Nr. 28, 1983, 22-29, hier: 28. 
Steigerung geht der Gedanke von der religiösen Provokation über den Tierschutz zur Sorge um eine Verunglimpfung der Polizei. Die Fäkalsprache und die Szene mit den beiden Polizisten, die quälend lang ausgespielt wird, sind auch nach meinen eigenen Erfahrungen in Diskussionsveranstaltungen zum Film die in spontanen Reaktionen am häufigsten genannten Elemente, weniger Szenen wie die des Gesprächs zwischen der Jesusfigur und der Oberin über das sakramentale Verständnis der Eucharistie, in der Jesus sich davon distanziert, Brot als seinen Leib zu betrachten.

\section{Skandalfilm mit Empfehlung: „Maria und Joseph“ (1985)}

Als Gegenstück zum Fall Achternbusch ist Jean-Luc Godards Film "Maria und Joseph" bemerkenswert in doppelter Hinsicht. Zum ersten Mal liegt hier ein Film vor, der von den professionellen Vertretern kirchlicher Filmarbeit empfohlen, von Vertretern der kirchlichen Hierarchie aber abgelehnt wird, zum anderen verbindet sich hier mit der Diskussion in besonderer Weise die Problematik der künstlerischen Form.

Dies erkannte schon die OCIC-Jury bei den Berliner Filmfestspielen 1985 (15.-26.02.). Zwar wurde die Erklärung zu Godards Film, der im Rahmen des Wettbewerbs seine internationale Erstaufführung erlebte, nicht gemäß den Statuten als "Lobende Erwähnung", sondern nur als "Statement" deklariert, aber der Inhalt legte die Unterstützung durch lobende Hervorhebung nahe. Die Jury erklärte: „Im Bewußtsein der Schwierigkeiten bzgl. der Originalität seiner Form und seines Themas möchte die OCIC-Jury einstimmig ihr Interesse an dem Film von Godard bekunden und den revolutionären Zugriff $\mathrm{zu}$ seinem Thema hervorheben. Mit großer Behutsamkeit greift Godard eine alte Glaubenswahrheit auf, um sich dem unerklärbaren Geheimnis der Liebe und des Lebens zu nähern. Er zeigt den Zusammenhang von Sinnlichkeit und Reinheit, von Naturwissenschaft und Metaphysik, die Versöhnung von Alltagserfahrung und Spiritualität. Die OCIC-Jury regt an, sich mit dem Film vorurteilsfrei auseinanderzusetzen. " 68

Die im „film-dienst" veröffentlichte Kritik von Hubert Haslberger verwies deutlich auf die "größte Gefahr [...] einer allzu direkten Gleichsetzung der beiden verschiedenen Zeit- und Bedeutungsebenen “69, d.h. der biblischen Geschichte und der Gegenwartsgeschichte, und stellte die positive Botschaft in ihrer komplexen Form heraus: "'Maria und Joseph' ist aber keine plump aktualisierende oder gar parodierende Paraphrase zum Neuen Testament. Im Gegenteil: Es geht

68 Zit.n. „Kirchliche Preise in Berlin”, in: film-dienst 38. Jg., Nr. 5, 06.03.1985, 149.

69 Hubert Haslberger, „Maria und Joseph" (fd 25050), in: film-dienst 38. Jg., Nr. $9,30.04 .1985,332 \mathrm{f}$. 
darum, mit gebrochener biblischer Metaphorik das Irdische, das Leben, die Liebe, die Mutterschaft wieder neu begreiflich zu machen. Und es geht um die heilsame Zertrümmerung platter Realitätsbegriffe und um die Wiederentdeckung des Wunderbaren im scheinbar Alltäglichen." Das komplexe Zitatengefüge, das auch das kalauernde Wortspiel miteinschließt, diene - so der Kritiker an die Adresse mancher Protestierender- „zweifellos der geistigen Auseinandersetzung mehr als die Versuche mancher Traditionalisten, die Heilsgeschichte in unantastbare ,nazarenische' Legendenhaftigkeit zu entrücken." (ebd.) Die Stellungnahme der Filmkommission unterstreicht unter Bezugnahme auf die Komplexität der Form nochmals die Anforderungen an den Zuschauer: „Der facettenreiche, durch seine Fülle an literarischen, philosophischen und theologischen Verweisen sehr anspruchsvolle Film bedarf der aufmerksamen Einlassung des Zuschauers." (ebd.)

Die Stellungnahme der Zentralstelle Medien vom 07.03.198570 versucht die Betroffenheit mancher Christen ernst zu nehmen, wirbt aber gleichzeitig um ein besseres Verständnis. Zugestanden wird als mögliche Wirkung, daß der Film "nicht leicht zugänglich" sei und "u.U. Betroffenheit auslösen” werde, der Film wolle aber keine „aktuelle Darstellung des Dogmas der Jungfrauengeburt sein“. Mit dem Hinweis auf den Widerspruch bei "nichtchristlichen Zeitgenossen" wird der Kern von Godards Film als Versuch gedeutet, „in Anlehnung an einen biblischen Stoff das Geheimnis des Lebens, seine Unverfügbarkeit und unantastbare Würde bildhaft auszudrücken und festzuhalten". Der Blasphemie-Verdacht wird durch eine eindeutige Bewertung der Intention entkräftet: „Vielleicht hilft es zu wissen, daß Godard es nicht im Sinn hatte, durch den Film Glaubensvorstellungen zu beleidigen." (ebd.) Die Stellungnahme fordert dazu auf, sich in mehrfacher Hinsicht mit dem Film auseinanderzusetzen, wobei der Film als Anlaß zu einer tieferen Versenkung in das Geheimnis der Menschwerdung Christi gewürdigt, ihm aber auch kritisch angekreidet wird, daß er "deren geschichtliche Dimension [...] kaum begriffen zu haben scheint."

Eine Erklärung des Ständigen Rates der Deutschen Bischofskonferenz am 29.04.198571 erhebt nicht den Blasphemie-Vorwurf, sondern argumentiert von einer verkürzten Rezeption her, die die eigentliche Intention nicht wahrnimmt: „Viele Gläubige [haben] den Eindruck, daß mit dem, was ihrer Frömmigkeit heilig ist, in einer dem Heilsereignis unangemessenen Weise gespielt wird." Eine inhaltliche Bewertung findet nicht statt, dafür wird die Formkritik um so schärfer formuliert: „Wenn auch nach Aussagen des Autors der Film keine Verhöhnung des katholischen Glaubens beabsichtigt, so verletzt er doch durch die Wahl seiner Mittel - angefangen vom Titel - viele Gläubige." Im letzten Absatz wird deutlich, daß der Ständige Rat sich nicht an das Urteil der

70 Zit.n. Film-Korrespondenz 31. Jg., Nr. 8, 23.04.1985, 1.

71 Zit.n. Film-Korrespondenz 31. Jg., Nr. 10, 21.05.1985, 12 f. 
eigenen kirchlichen Experten anlehnt, sondern sich auf das Urteil des Vorsitzenden der Publizistischen Kommission der Französischen Bischofskonferenz, Msgr. Jean Bernard, dem Bischof von Nancy, gestützt hat bzw. die bei Achternbusch aufgegriffene Diskussion um künstlerische Freiheit und deren soziale Einbindung erneut aufgreift, indem sie auf die Rücksichtnahme auf die Überzeugungen anderer als notwendiges Korrelat zur Freiheit verweist, ohne jedoch Godard nachzuweisen, daß er diese Rücksichtnahme bewußt vernachlässigt habe.

Die große Chance, die der Film nach Auffassung der kirchlichen Filmexperten bot, über den Film eine zeitgemäße Annäherung an wichtige Glaubensinhalte $\mathrm{zu}$ versuchen, wurde letztlich nicht genutzt, weil doch die Bedenken, die sich in der Stellungnahme des Ständigen Rates niederschlagen, überwogen. Die Befürworter des Films traf damals schon zum Teil heftige Kritik aus Kirchenkreisen. Im Gegensatz zum Achternbusch-Film, der noch heute Kontroversen auslösen kann, hat sich die Entrüstung über Godards Film gelegt. Heute hört man dagegen eher Kritik aus dem Lager der Kirchenfernen, die es wieder für "typisch katholisch" halten, daß ein künstlerisch progressiver Film, der wider Erwarten die Jungfrauengeburt ganz ernst nimmt, eine Empfehlung erhalten hat.

\section{Skandal um eine Vision des Teufels: „Die letzte Versuchung Christi"}

Der letzte große Skandalfall ist Martin Scorseses Film "Die letzte Versuchung Christi" (1988) nach dem Roman des griechischen Nobelpreisträgers Nikos Kazantzakis, der nach seinem Erscheinen auf den kirchlichen "Index" für Bücher gekommen war. Gab es schon bei Godards Film Vorberichte über die Debatten in Frankreich, wurde der Skandal im Fall Scorsese aus den Vereinigten Staaten importiert. Nachdem der Film schon in seiner mehr als zwölfjährigen Entstehungszeit bei Bekanntwerden des Projekts Proteste hervorgerufen hatte, ging der Sturm mit den ersten Aufführungen des Films erst richtig los. Bereits in den Sommermonaten setzten die Demonstrationen ein. Sie boten ein Bild, das sich in Abwandlung in verschiedenen Ländern wiederholen sollte: „Ein ungewohnter Anblick bot sich amerikanischen Kinogängern am 12. August 1988. Lange Besucherschlangen standen vor den Eingangstüren, bis weit um die Straßenecke des nächsten Häuserblocks herum. Vor der Kasse patroullierten Menschen mit Demonstrationsschildern, andere umrundeten die auf Einlaß Wartenden laut betend, mit Rosenkränzen in den Händen. Als sich die Türen öffneten, wähnte man sich für einen Augenblick wie auf einem internationalen Flughafen: Nicht nur die Eintrittskarten wurden gefordert, sondern Sicherheitsbeamte kontrollierten jede noch so kleine Handtasche. Drinnen im Kino begann der Film pünktlich, doch rechts und links von der Leinwand entdeckte man unschwer zwei Sicherheitsoffiziere mit sturzhelmähnli- 
cher Kopfbedeckung, die während der ganzen Vorstellung das Publikum im Auge behielten."72

Die von Aggressivität und Hysterie getragenen Proteste in den USA hatten gefährliche Züge: antisemitische Tendenzen, die in den Aktionen gegen den jüdischen Produzenten des Films sichtbar wurden, waren Ausdruck einer Intoleranz der Filmgegner, die man Scorseses Film nicht vorwerfen konnte.

Noch vor dem europäischen Start des Films auf den Filmfestspielen in Venedig am September 1988 formierten sich die Proteste. Im August verbreitet die Evangelische Marienschwesterschaft Darmstadt Warnungen vor dieser "hereinbrechende[n] Flut der Gotteslästerung ".73 Beigefügt ist dem Schreiben ein Bericht über den Inhalt des Films, der aus dem Amerikanischen übersetzt wurde, und mit detaillierten Beschreibungen (,Jesus nackt am Kreuz. Schamhaare sind zu sehen, aber nicht die Geschlechtsteile."; 5) aufwartet. Verfasserin ist Evelyn Dukovic, die Vize-Präsidentin der Organisation „Morality in Media, Inc.", New York.

In einer Stellungnahme für eine Pressekonferenz am 09.08.1988 formuliert Mutter Basilea Schlink die Ablehnungsargumente: 1. Jesus werde als "Lüstling" dargestellt. 2. Er werde als Schwächling voll Furcht und Sünde dargestellt. 3. Der Film sei eine "der raffiniertesten Verführungen und Blasphemien, welche die Welt je gesehen hat, eine Verflechtung von Obszönitäten und mißbrauchten Bibelzitaten, wobei Schmählichstes, Gemeinstes über Jesus ausgesagt wird.“ Die Stellungnahme endet mit dem warnenden Hinweis auf die Strafe Gottes, unterlegt mit dem Zitat: "Irret euch nicht, GOTT läßt sich nicht spotten" (Gal 6,7).

Als der Film erstmals auf den Filmfestspielen in Venedig gezeigt wurde, veröffentlichte die OCIC eine Stellungnahme, die die Enttäuschung der kirchlichen Filmexperten über die Unzulänglichkeiten der Bildästhetik zum Ausdruck brachte. Anerkannt wurde, daß der Film Anstoß erregen könne, aber die Stellungnahme enthält abschließend auch den Ausdruck des Bedauerns angesichts der hysterie-ähnlichen Erscheinungen in Amerika. ${ }^{74}$

Eine Flut von Protestschreiben, von denen der überwiegende Teil die vorformulierten Argumente der evangelischen Marienschwestern

72 Franz Everschor, „Umstrittener neuer Christusfilm,” in: Film-Korrespondenz 34. Jg., Nr. 18, 30.08.1988, 1f, hier: 1.

73 Schreiben von Mutter Basilea Schlink vom 15.08.1988 (nach den Akten der Zentralstelle Medien).

74 Zit.n. der Meldung: „Von Scorsese-Film enttäuscht”, in: film-dienst 41. Jg., Nr. 18. 06.06.1988, 1039. 
kopierte, veranlaßte die Bischöfe zu einer eigenen Stellungnahme anläßlich der Herbstvollversammlung ${ }^{75}$, noch bevor die deutsche Fassung vorlag. Darin drückten sie ihr Befremden darüber aus, daß "ein solcher Film überhaupt dem Publikum zugemutet wird". Kern der Stellungnahme ist eine scharfe Zurückweisung des Inhalts: „In völliger Willkür verfälscht und verzerrt der Film die biblische Gestalt Jesu. Er beleidigt die religiösen Gefühle der Gläubigen.". Ebenso harte Vorwürfe treffen den Autor: "Wer in dieser Weise die Überzeugungen anderer verletzt, verhält sich intolerant und kann sich dafür nicht auf die Freiheit der Kunst berufen.“ Gegenüber früheren Stellungnahmen zu anderen Filmen, die noch stärker argumentativ angelegt waren, wird hier das Urteil auf wenige apodiktische Sätze reduziert, die vom Ton der Protestbriefe nicht weit entfernt sind.

Der "film-dienst" beschäftigte sich ausführlich mit dem Film. In der Kritik von Hans Gasper, Referent für Grundsatzfragen und Sektenexperte in der Zentralstelle Pastoral, werden die ästhetischen und theologischen Probleme des Films beleuchtet. Die Kritik stellt deutlich die Differenz zwischen dem Jesusbild der Heiligen Schrift und dem Jesusbild von Kazantzakis und Scorsese heraus. Der am meisten umstrittenen Traumsequenz wird eine "gewisse Zweideutigkeit" attestiert, aber es werden auch durchaus diskussionswerte Bezüge erkannt: "Ausgerechnet in jener Sequenz, die am meisten Aufregung verursacht hat, bekommt der Film noch am meisten Boden unter die Füße: Die Urversuchung des von Gott Erwähiten, sich davon zu machen (Jona!) trotz der Banalitäten und auch Geschmacklosigkeiten dieses Abschnitts. ${ }^{476}$

Die zusammenfassende Stellungnahme der Katholischen Filmkommission kam zu dem Ergebnis: „Der in mehreren Darstellungen biblischer Episoden plakative und enttäuschend flache Film stellt sich durch sein Gottesbild und die Zeichnung Jesu Christi in grundsätzlichen Widerspruch zur christlichen Heilsbotschaft. In ihrem ikonographischen Charakter wirken die Bilder ohne spirituelle Kraft und verfehlen den zentralen Aspekt des christlichen Glaubens, die erlösende Anteilnahme Gottes am existentiellen Sein des Menschen. Zuschauer, die den dargestellten Jesus als Jesus der Bibel (miß-)verstehen, können zu Recht Anstoß nehmen." In einem weiteren umfangreichen Aufsatz von Karl-Eugen Hagmann wurde die theologische und ästhetische Bewertung noch weiter vertieft. ${ }^{77}$

75 Zit.n. der Meldung: „Bischöfe zu Scorsese-Film“, in: film-dienst 41. Jg., Nr. 20, 04.10.1988, 1212 .

76 Hans Gasper, „Die letzte Versuchung Christi” (fd 27169), in: film-dienst 41. Jg., Nr. 22, 03.11.1988, 1284-1286, hier: 1285.

7 Karl-Eugen Hagmann, "Geisel in Gottes Hand", in: film-dienst 41. Jg., Nr. 23, 05.11.1988, 1339-1344. 
Die in vielen Protesten artikulierte Unterstellung, Scorsese habe mit einem pornographischen Film Kasse machen wollen, ist ebenso wenig haltbar wie die Unterstellung einer blasphemischen oder bewußt verletzenden Absicht. Paul Schrader, der Drehbuchautor, dessen Vorstellungen neben denen von Kazantzakis und Scorsese das Bild des Films geprägt haben, sah den Film nicht als Provokation, sondern als Angebot zu einer theologischen Debatte: "I come from a background where theological debate is a staple, and considered conducive to faith rather than detrimental to it. It was fundamentalist, but it was intellectually oriented rather than faith oriented, which is the inheritance of John Calvin: Christianity is basically logic. Most of the people who protested came from another aspect of Christianity where it's practically all faith. ${ }^{\prime 78}$

Scorseses Vorstellung war, daß der Film einen Jesus präsentieren sollte, dem auch Versuchungen nicht fremd waren, der daher durch seine menschliche Natur für die Zuschauer eine besondere Nähe gewinnt (, a Jesus you could sit down with ${ }^{479}$ ), so daß der Film wie das Buch genutzt werden könne, "not as a substitute for the Gospel, but as a parable that is fresh and alive ${ }^{\mu / 80}$.

Der Film ist nach Auffassung des Drehbuchautors Paul Schrader interessant durch seinen "layer cake aspect of Christian theology ${ }^{\prime 81}$ in seiner Verknüpfung von griechisch-orthodoxen (Kazantzakis), calvinistischen (Schrader) und römisch-katholischen (Scorsese) Elementen, und zugleich ist er eine naive psychologisierende Verarbeitung kindlicher Bilder des Regisseurs82, den die fundamentalistische Kritik trifft, die sich gleichermaßen gegen andere theologische Richtungen wendet: „Indem er [d.h. Scorsese] Jesus nach seinem eigenen Bild erschafft, stellt er sich in eine Reihe mit einer Vielzahl von modernen sektiererischen Theologen, die nichts anderes tun als das. ${ }^{~} 83$

Bei Scorseses Film und den zuvor erwähnten Beispielen der 80er Jahre spitzte sich die Blasphemie-Diskussion noch einmal zu. Dabei wird auch von den Fachleuten gern übersehen, daß die Vokabel in den offiziellen kirchlichen Stellungnahmen und in der Kritik nicht vorkommt. In Diskussionen darüber wird gern darauf verwiesen, daß es eine prominente Reihe von vermeintlichen Ketzern gibt, die dem

78 Schrader on Schrader \& Other Writings, ed. Kevin Jackson. London/Boston, 1990, 137.

79 Scorsese on Scorsese. Ed. David Thompson, Ian Christie. London/Boston $1989,117$.

80 Ebd., 124.

81 Schrader, a.a.O., 137.

82 Vgl. Scorsese, a.a.O., 118.

83 John Ankerberg/John Weldon, Standpunkt: Die letzte Versuchung Christi. Asslar 1988, 54. Das schmale Bändchen wurde in Deutschland noch vor dem Start des Films veröffentlicht. 
Blasphemie-Vorwurf ausgesetzt waren, und Jesus selbst der Gotteslästerung angeklagt worden ist. Das Phänomen hat am eindringlichsten Reinhold Zwick analysiert ${ }^{84}$, der die verschiedenen Ursachen und Motive der Blasphemie untersucht hat und in der Beurteilung der Geschichte der filmischen Blasphemien zu dem Ergebnis kommt, daß „immer wenigstens vier Faktoren, die alles Urteilen konditionieren und permanent relativieren," im Spiel sind: 1. die aktuelle geistig-emotionale Verfassung, 2. gruppenspezifische Überzeugungen, 3. individuelle Wertmaßstäbe und ureigenes religiöses Empfinden, 4. der künstlerische Charakter des Werkes. Diese Relativierungen, die zur Folge haben, daß es selten Einigkeit über ein Urteil gibt, mahnen - so Zwick - "zu besonderer Umsicht bei der Rede von Blasphemie, heben aber keineswegs deren Sinnhaftigkeit auf." Es gibt nach Auffassung von Zwick gewollte blasphemische Akte, die den Christen auch zu einer Stellungnahme herausfordern.

Gerade an den meisten der zuvor diskutierten Beispiele ist der Blasphemie-Vorwurf als Unterstellung einer Intention nicht zu erhärten. Allenfalls bei Achternbusch kann man Züge eines bewußt blasphemischen Aktes unterstellen, wenn auch seine eigene Identifikation mit dem Jesus, den er selbst als eine Narrenfigur spielt, die von Vertretern der Macht, der Staatsgewalt wie der Kirche, mißbraucht wird, und die Überwindung aller Macht, aller Angst und alles Irdischen herbeisehnt, die Frage aufwirft, inwieweit hinter den offensichtlichen Haßtiraden nicht auch eine Nähe erkennbar ist. Wenn das Werk eines Regisseurs die Ernsthaftigkeit seiner Absichten bekräftigt, ist es problematisch, ihm eine intolerante Absicht zu unterstellen, wenn - wie das Beispiel Scorsese zeig $t$ - er nach eigener Auffassung gerade darum bemüht war, Jesus den Kirchenfernen nahezubringen, wie immer man den Erfolg seiner Bemühungen beurteilen mag. Auch stellt sich die Frage nach der sozialen Verantwortung des Künstlers auch im Hinblick auf die Provokation: es kann geradezu eine Verpflichtung sein, die Menschen durch Provokationen aufzurütteln, wenn dies Fehlentwicklungen und Mißstände aufdeckt.

Bei den letztgenannten Beispielen der 80er Jahre sowie auch bei den meisten früheren Skandalfilmen ist der Blasphemie-Vorwurf in strengem Sinn nicht zu halten. Es zeigt sich hier stets die Differenz von "Interpretation" und "Gebrauch" im Sinne Umberto Ecos 85 , wonach mit Interpretation" die Realisierung der im Text angelegten Lesarten gemeint ist, während ,Gebrauch" alle Rezeptionsweisen umfaßt, die durchaus ihre Legitimation haben, aber an der Textintention vorbeigehen und Mißverständnisse, Verzerrungen oder andere Störungen der

84 Reinhold Zwick, „Blasphemie im Film. Motive und Probleme der Bewertung", in: Katechetische Blätter 116. Jg., H. 7-8/1991, 540-549.

85 Umberto Eco, Lector in fabula. Die Mitarbeit der Interpretation in erzählenden Texten, München 1990, $72 \mathrm{ff}$. 
Rezeption miteinschließen. Alle Blasphemievorwürfe sind in der Regel gestützt durch eine unterstellte Rezeption, die einzelne Szenen aus dem Kontext reißt oder über Gebühr herausstellt und andere Aspekte unterschlägt. Der empirische Nachweis, daß eine derartige Rezeption tatsächlich vorkommt, wird unmöglich, wenn die Protestierenden ohne eigene Kenntnis des Films ihre Meinung vortragen.

Gerade bei den Auseinandersetzungen um die Filme der 80er Jahre wird zunehmend deutlich, daß sich auf der einen Seite durchaus engagierte Christen zu Wort melden, die aufgrund der fehlerhaften Information im guten Glauben handeln, protestieren zu müssen - häufig mit dem Hinweis darauf, daß andere dies schon getan haben -; auf der anderen Seite melden sich zahlreiche Schreiber, deren Meinungen oft gefährlicher sind als die Inhalte des Films. So werden antisemitische Tendenzen in Äußerungen zur "Letzten Versuchung“ erkennbar, oder es werden fundamentalistische Positionen des Islams gegenüber vermeintlichen Häretikern als vorbildhaft hingestellt. Der Film wird nicht selten zum Anlaß genommen, den Ärger über Tendenzen in Politik und Kultur loszuwerden. So kommt es zu Ausfällen gegen die , atheistischen Liberalen und CDU-Heuchler', der Untergang des Abendlandes wird beschworen und der Film als Spitze einer Entwicklung gesehen, die mit Nacktbaden, Sexualaufklärung an Schulen, Pille, Abtreibung usw. schon Zeichen des Antichristen gesetzt hat.

Ebenso heftig sind die Reaktionen derer, die der Kirche jedes Recht auf eine Stellungnahme absprechen. Gerade in persönlichen Begegnungen bei Diskussionen spürt man sehr schnell, daß nicht allein der Film Auslöser für heftige Reaktionen ist, sondern eher persönliche negative Erfahrungen mit der Kirche, so daß die Diskussion über einen Film, der die Kirche wieder als Zensurinstanz erscheinen läßt, Attacken hervorruft, die individualpsychologisch motiviert sind. Man attackiert den Film, um die Ungläubigen zu treffen, oder man attackiert die Kirche. Es ist kein Einzelfall, daß bei Diskussionen um einen Skandalfilm dem Kirchenvertreter sehr schnell das ganze ,Sündenregister' der Kirche (der Fall Galilei, die Hexenverfolgung, die Machtpolitik, die Prunksucht des Vatikans etc.) um die Ohren geschlagen wird.

\section{Bilanz}

In der Auseinandersetzung um die Skandalfilme lassen sich Entwicklungslinien erkennen:

1. Die Gruppen der Betroffenen verändern sich. Während im Fall der "Sünderin" noch die ganze Breite des katholischen sozialen Milieus mobilisiert wird und die Ablehnung von der Jugend über die Verbände bis hin zur Hierarchie einhellig ist, gibt es spätestens seit den 60er Jahren deutlich unterschiedene Lager. Im Falle des "Schweigens" steht die katholische Filmkritik und die Filmkommissi- 
on gegen viele Vertreter der kirchlichen Hierachie und gegen Bereiche der säkularen Öffentlichkeit mit einer differenzierten Würdigung. Im Fall der "Letzten Versuchung" ist es soweit gekommen, daß der eigentliche Protest in völliger Unkenntnis des Werkes sich in einer Flut von Formbriefen äußert, die zum größten Teil nicht von katholischer, sondern von evangelischer Seite angestoBen worden sind.

2. Die Kompetenz der professionellen katholischen Filmkritik ändert sich. Ist der Ansatz auch mit dem Ziel des mündigen Zuschauers zunächst noch unter dem Eindruck der Erfahrungen des NaziRegimes vor allem bewahrpädagogisch ausgerichtet, so weitet sich der Ansatz immer mehr auf ein dialogisches Denken hin. Mit zunehmender filmanalytischer Kompetenz gewinnt die Bedeutung der formalästhetischen Seite einen gewichtigen Stellenwert, die von Anfang an angestrebte "ganzheitliche Schau“ wird zunehmend verwirklicht.

3. Die Motive, die hinter den Reaktionen auf Skandalfilme stehen, ändern sich: ist die Zurückhaltung der katholischen Filmkritik in vielen Fällen taktisch motiviert, um dem Film nicht durch eine öffentliche Verlautbarung erst zum Skandal zu machen, so wird zunehmend die Komplexität gewürdigt. Die Würdigung auch komplexer ästhetischer Konstruktion läßt keine apodiktischen Urteile mehr zu.

4. Die Argumente in den Debatten ändern sich: während in den 50er und 60er Jahren die sittlich-moralischen Normen im Vordergrund stehen, verlagert sich die Diskussion in den 80er Jahren zunehmend auf die Frage der Kunstfreiheit. Dabei ist auch zu beobachten, daß die Qualität der Kritiken zunimmt, während die Stellungnahmen der Amtskirche eher an Argumentationsbreite verlieren, so daß im Fall Scorsese nur noch auf Standardformulierungen reduzierte Urteile abgegeben werden.

5. Einwände vieler Protestierender können kaum ernsthaft gewürdigt werden, weil sie in den meisten Fällen nicht auf einer eigenen Sichtung beruhen, sondern auf verzerrenden Darstellungen aus zweiter Hand. Zudem mischen sich unterschiedliche Motive in den Protest: Artikulation eines allgemeinen Unbehagens, gezielte Kritik an gesellschaftlichen und politischen Institutionen und persönliche Verletztheiten.

Die Tatsache, daß bestimmte Filme Proteste hervorrufen, ist nicht von vornherein negativ zu bewerten. Die Provokation des Rezipienten, der Versuch, durch Provokation eingefahrene Sehweisen neu zu überdenken, ist ein legitimes Verfahren der Künste. Die Proteste können sogar für das Gelingen des Films sprechen. Gäbe es keine Proteste, hätte der Film sein Ziel verfehlt. Ebenso legitim ist die Frage, wie die Provokation 
zu beurteilen ist, welche Ziele sie verfolgt und welchen Sinn die intendierten Denkanstöße vermitteln wollen.

Das Fazit bei allen Skandalfilmen ist dies: obwohl die Filme mehr als alle anderen diskutiert worden sind, wurden die eigentlichen Diskussionen, die lohnenswert gewesen wären, kaum geführt. Das "Schweigen" war nicht Anlaß, um über die Erfahrungen des modernen Menschen, der Gott als Schweigenden empfindet, zu diskutieren, sondern ein Streit um sexuell abstoßende Szenen, die so wirkten, wie sie wirken sollten. Bei „Maria und Joseph" gab es keine Diskussion über die Frage nach einer zeitgemäßen Vermittlung der großen Geheimnisse des Lebens und der Liebe, sondern Aufgeregtheiten um eine nackte Maria und vulgäre Sprache. Die "Letzte Versuchung Christi" war kein Anlaß, über unsere Jesus- und Gottesbilder und unser heutiges Verständnis der Doppelnatur Jesu so offen zu sprechen, wie Scorsese sein Bekenntnis und seine eigenen Vorstellungen im Film ausdrückt, sondern man stritt um eine zum Zwecke der Verdeutlichung erfundene Vision des Teufels. Fast müßte man sich einen hochkarätigen, Skandalfilm' wünschen, der unbequeme Denkanstöße gibt, die auch so aufgegriffen werden, daß sie zu einer wirklich breiten und tiefgehenden theologischen Debatte über religiöse Erfahrungen in unserer Zeit führen.

SUMMARY: From Defence to Dialogue: Catholic Controversies about Scandalous Films

This article provides a detailed outline about the ways the official Catholic Church has dealt with so called scandalous films'. The focus is on films made in the period from the fifties to the eighties. Films like ,Die Sünderin' (1950), 'The silence' (1963), ,Teorema' (1968), Life of Brian' (1980), 'Das Gespenst' (1982), ,Marie and Joseph' (1985) and ,The Last Temptation of Christ' (1986) are taken to exemplify the issue.

The analysis of the (often mixed) reactions of the Church - of Catholic laymen, bishops and Catholic experts for film - has shown important changes during the recent decades. Initially, the way of argumentation was protective pedagogical and it was even thought about censorship to prevent a state of uncertainty among the uneducated believers. Later on, the ,enlightened and mature spectator' moved into the focus of attention. Modern films were not only assessed at its presumed ,immoral' content, but also at its aesthetic and formal standards.

Today the quality of ,Catholic' film critique (for comparison, e.g. the magazine ,film-dienst') is generally accepted and respected. However, even today some bishops do not take enough into account the opinions of the film experts of the Church and act extremely rigorous. In consideration of this, the authors conclusion is that today there does exist a gap between the assessment of ,official' Catholic film critics and the judgements of bishops. 
RÉSUMÉ: Des actions défensives à un début de dialogue: Les querelles à propos des films à scandale dans le travail cinématographique catholique

L'auteur nous présente un aperçu détaillé qui s'efforce de nous livrer des données exactes en ce qui concerne la façon d'agir de l'eglise catholique officielle de l'Allemagne Fédérale avec les soi-disant films a scandále. 11 s'agit de la période qui s'étend des années 50 aux années 80 où l'on s'intéresse, à titre d'exemples, aux films ,La pêcheresse' (1950), ,Le silence“ (1963), ,Teorema“ (1968), ,La vie de Brain' (1980), ,Le fantôme' (1982), ,Marie et Joseph' (1985) et ,La dernière tentation du Christ' (1986).

L'analyse (souvent différente) des réactions de l'église - par des groupes lais catholiques, les évêques, les experts en film de l'église - montre des changements importants au cours des décennies. Tout d'abord, on a argumenté d'une façon pédagogique protectionniste et on a aussi pensé à l'instrument de la censure pour éviter un "trouble chez les croyants incultes". Plus tard, le „spectateur majeur et éclairé” a été replacé au centre de l'attention. Le film moderne n'a plus été seulement jugé d'après son contenu - soi-disant „immoral" -, mais d'aprés ses critères esthétiques et formels.

Aujourd hui, la qualité de la critique cinématographique catholique (voir par ex. la revue ,film-dienst') est généralement reconnue et appréciée. Quelquefois les évêques agissent pourtant encore aujourd'hui de façon très rigoureuse, sans s'intéresser aux jugements émis par les spécialistes de leur propre église. C'est la raison pour laquelle l'auteur en conclut qu'il existe souvent de nos jours un fossé entre les appréciations des critiques de films catholiques officiels et les jugements des évêques.

RESUMEN: Desde las acciones defensivas hasta llegar a los comienzos del diálogo: las disputas en torno a las películas escandalosas en la crítica filmográfica católica

El autor nos entrega una detallada visión, en la que se manifiesta un gran interés por la exactitud histórica, acerca del tratamiento que la iglesia católica oficial de la República Federal de Alemania dio a los llamadas "películas escandalosas". Se trata del tiempo comprendido entre los años 50 y los 80, utilizando para ello a título de ejemplo las películas ,La pecadora' (1950), ,El silencio' (1963), ,Teorema' (1968), ,La vida da Brian' (1980), ,El fantasma' (1982), 'María y José' (1985) y, La última tentación de Cristo' (1986).

El análisis de las reacciones de la iglesia (frecuentemente no uniformes) efectuada por grupos de laicos católicos, por obispos, por expertos en películas de la iglesia - muestra a través de los años cambios fundamentales: primeramente se arguyeron argumentos de „pedagogía de protección” y se pensó también en el instrumento de la censura como una forma de impedir una "inseguridad de los creyentes sin formación". Después el centro de atención se fijó en "los espectadores críticos y maduros". El film moderno pasó a no ser juzgado ya más tan solo según su presumible „inmoralidad", sino también según sus medidas formales y estéticas. Hoy en día la crítica filmográfica "católica" goza de reconocimiento y aprecio general (ver p.e. la revista "film-dienst"). Sin embargo, de cuando en cuando los obispos actúan aún hoy en forma muy rigurosa, sin escuchar suficientemente el juicio de las instancias especializadas de la iglesia. De ahí que el autor llegue al resultado de que hace un abismo entre las valoraciones de los críticos filmográficos católicos „oficiales” y el juicio de los obispos. 